\title{
Monetary Policy Drivers of Bond and Equity Risks
}

\section{Citation}

Campbell, John Y., Carolin Pflueger, Luis Manuel Viceira. 2014. "Monetary Policy Drivers of Bond and Equity Risks." NBER Working Paper no. 20070.

\section{Permanent link}

http://nrs.harvard.edu/urn-3:HUL.InstRepos:14609095

\section{Terms of Use}

This article was downloaded from Harvard University's DASH repository, and is made available under the terms and conditions applicable to Open Access Policy Articles, as set forth at http:// nrs.harvard.edu/urn-3:HUL.InstRepos:dash.current.terms-of-use\#OAP

\section{Share Your Story}

The Harvard community has made this article openly available.

Please share how this access benefits you. Submit a story.

Accessibility 
NBER WORKING PAPER SERIES

MONETARY POLICY DRIVERS OF BOND AND EQUITY RISKS

\author{
John Y. Campbell \\ Carolin Pflueger \\ Luis M. Viceira \\ Working Paper 20070 \\ http://www.nber.org/papers/w20070
NATIONAL BUREAU OF ECONOMIC RESEARCH
1050 Massachusetts Avenue
Cambridge, MA 02138
April 2014

We are grateful to Alberto Alesina, Yakov Amihud, Robert Barro, Philip Bond, Mikhail Chernov, Paul Beaudry, Ian Dew-Becker, Alexander David, Adlai Fisher, Ben Friedman, Lorenzo Garlappi, Joao Gomes, Gita Gopinath, Robin Greenwood, Joshua Gottlieb, Howard Kung, Leonid Kogan, Deborah Lucas, Greg Mankiw, Harald Uhlig, Michael Woodford, conference and seminar participants at the University of British Columbia, the Harvard Monetary Economics Seminar, the 2013 HBS Finance Research Retreat, the University of Calgary, the University of Miami, the Vienna Graduate School of Finance, ECWFC 2013, PNWCF 2014, the Jackson Hole Finance Conference 2014, the ASU Sonoran Winter Finance Conference 2014, the Monetary Policy and Financial Markets Conference at the Federal Reserve Bank of San Francisco, the Adam Smith Asset Pricing Workshop, NYU Stern School, the Federal Reserve Bank of New York, the Bank of Canada, and especially our discussants Gregory Duffee, Martin Lettau, Rossen Valkanov, Jules van Binsbergen, and Stanley Zin for helpful comments and suggestions. This material is based upon work supported by Harvard Business School Research Funding and the PH\&N Centre for Financial Research at UBC. The views expressed herein are those of the authors and do not necessarily reflect the views of the National Bureau of Economic Research.

NBER working papers are circulated for discussion and comment purposes. They have not been peerreviewed or been subject to the review by the NBER Board of Directors that accompanies official NBER publications.

(C) 2014 by John Y. Campbell, Carolin Pflueger, and Luis M. Viceira. All rights reserved. Short sections of text, not to exceed two paragraphs, may be quoted without explicit permission provided that full credit, including $\odot$ notice, is given to the source. 
Monetary Policy Drivers of Bond and Equity Risks

John Y. Campbell, Carolin Pflueger, and Luis M. Viceira

NBER Working Paper No. 20070

April 2014

JEL No. E43,E44,E52,G12

\begin{abstract}
$\underline{\text { ABSTRACT }}$
The exposure of US Treasury bonds to the stock market has moved considerably over time. While it was slightly positive on average in the period 1960-2011, it was unusually high in the 1980s and negative in the 2000s, a period during which Treasury bonds enabled investors to hedge macroeconomic risks. This paper explores the effects of monetary policy parameters and macroeconomic shocks on nominal bond risks, using a New Keynesian model with habit formation and discrete regime shifts in 1979 and 1997. The increase in bond risks after 1979 is attributed primarily to a shift in monetary policy towards a more anti-inflationary stance, while the more recent decrease in bond risks after 1997 is attributed primarily to a renewed emphasis on output stabilization and an increase in the persistence of monetary policy. Endogenous responses of bond risk premia amplify these effects of monetary policy on bond risks.
\end{abstract}

John Y. Campbell

Morton L. and Carole S.

Olshan Professor of Economics

Department of Economics

Harvard University

Littauer Center 213

Cambridge, MA 02138

and NBER

john_campbell@harvard.edu

Carolin Pflueger

Sauder School of Business

University of British Columbia

2053 Main Mall

Vancouver, BC, V6T 1 Z2

Canada

carolin.pflueger@sauder.ubc.ca
Luis M. Viceira

George E. Bates Professor

Harvard Business School

Baker Library 367

Boston, MA 02163

and NBER

lviceira@hbs.edu

An online appendix is available at:

http://www.nber.org/data-appendix/w20070 


\section{Introduction}

In different periods of history, long-term US Treasury bonds have played very different roles in investors' portfolios. During the Great Depression of the 1930s, and once again in the first decade of the 21st Century, Treasury bonds served to hedge other risks that investors were exposed to: the risk of a stock market decline, and more generally the risk of a weak macroeconomy, with low output and high unemployment. Treasuries performed well both in the Great Depression and in the two recessions of the early and late 2000s. During the 1970s and particularly the 1980s, however, Treasury bonds added to investors' macroeconomic risk exposure by moving in the same direction as the stock market and the macroeconomy. A number of recent papers including Baele, Bekaert, and Inghelbrecht (2010), Campbell, Sunderam, and Viceira (2013), Christiansen and Ranaldo (2007), David and Veronesi (2013), Guidolin and Timmermann (2006), and Viceira (2012) have documented these developments.

In this paper we ask what macroeconomic forces determine the risk properties of US Treasury bonds, and particularly their changes over time. One common approach to this question uses identities that link bond returns to movements in bond yields, and that link nominal bond yields to expectations of future short-term real interest rates, expectations of future inflation rates, and time-varying risk premia on longer-term bonds over short-term bonds. Barsky (1989), Shiller and Beltratti (1992), and Campbell and Ammer (1993) were early examples of this approach. A more recent literature has proceeded in a similar spirit, building on the no-arbitrage restrictions of affine term structure models (Duffie and Kan 1996, Dai and Singleton 2000, 2002, Duffee 2002) to estimate multifactor term structure models with both macroeconomic and latent factors (Ang and Piazzesi 2003, Ang, Dong, and Piazzesi 2007, Rudebusch and Wu 2007). Although these exercises can be informative, they 
are based on a reduced-form econometric representation of the stochastic discount factor and the process driving inflation. This limits the insights they can deliver about the economic determinants of bond risks.

A more ambitious approach is to build a general equilibrium model of bond pricing. Real business cycle models have an exogenous real economy, driven by shocks to either goods endowments or production, and an inflation process that is either exogenous or driven by monetary policy reactions to the real economy. Papers in the real business cycle tradition often assume a representative agent with Epstein-Zin preferences, and generate time-varying bond risk premia from stochastic volatility in the real economy and/or the inflation process (Bansal and Shaliastovich 2013, Buraschi and Jiltsov 2005, Burkhardt and Hasseltoft 2012, Gallmeyer et al 2007, Piazzesi and Schneider 2006). Some papers instead derive time-varying risk premia from habit formation in preferences (Bekaert, Engstrom, and Grenadier 2010, Bekaert, Engstrom, and Xing 2009, Buraschi and Jiltsov 2007, Dew-Becker 2013, Wachter 2006). Under either set of assumptions, this work allows only a limited role for monetary policy, which determines inflation (at least in the long run) but has no influence on the real economy. ${ }^{2} \quad$ Accordingly a recent literature has explored the asset pricing implications of New Keynesian models, in which price stickiness allows monetary policy to have real effects. Recent papers in this literature include Andreasen (2012), Bekaert, Cho, and Moreno (2010), Van Binsbergen et al (2012), Dew-Becker (2014), Kung (2013), Li and Palomino (2013), Palomino (2012), Rudebusch and Wu (2008), and Rudebusch and Swanson (2012).

We follow this second approach and quantitatively investigate two candidate explanations for the empirical instability in bonds' risk properties: changes in monetary policy or changes

\footnotetext{
${ }^{2} \mathrm{~A}$ qualification to this statement is that in some models, such as Buraschi and Jiltsov (2005), a nominal tax system allows monetary policy to affect fiscal policy and, through this indirect channel, the real economy.
} 
in macroeconomic shocks. US monetary policy has altered substantially between the period of rising inflation in the 1960s and 1970s, the inflation-fighting period under Federal Reserve Board chairmen Paul Volcker and Alan Greenspan and, as we newly identify in our analysis, the most recent period of increased central bank transparency, gradualism, and renewed attention to output stabilization. If the central bank affects the macroeconomy through nominal interest rates, it is natural to think that these changes should affect the risks of bonds and stocks. The nature of economic shocks has also changed over time. While oil supply shocks were prominent during the 1970s and 1980s, more recent output fluctuations have been associated with the information technology revolution and shocks to the financial sector. It is intuitive that whenever supply shocks are dominant, bonds should be risky assets. Macroeconomic supply shocks, such as the oil supply shocks of the 1970s and 1980s, might generate high-inflation recessions and therefore lead bonds to perform poorly at the same time as stocks.

Figure 1 helps motivate our analysis, showing a timeline of changing US bond risks, monetary policy regimes, and oil price shocks from Hamilton (2009). Figure 1 measures bond risks with filtered estimates of CAPM betas and return volatilities using daily returns on tenyear nominal bonds. Before 1979, the beta of bonds was close to zero but slightly positive. The bond beta became strongly positive during the 1980s and 1990s, but it declined sharply and turned negative in the late 1990s. Figure 1 also shows two dates that correspond to shifts in monetary policy. The first monetary policy break date corresponds to the appointment of Paul Volcker as chairman of the Federal Reserve Board, which arguably marked a significant change from the previous more accommodative monetary policy regime (Clarida, Gali, and Gertler 1999). The second monetary policy break date marks the first quarter of 1997 , coinciding with Alan Greenspan's well known "Central Banking in a Democratic Society" 
speech (Greenspan 1996). At first glance, monetary policy changes in the late 1990s might not be as salient as Paul Volcker's appointment. However, we show that this was a period of significant monetary policy shifts towards transparency and gradualism and a renewed emphasis on output stabilization, with the central bank being more aware of its influence on financial markets, taking more cautious interest rate decisions, and implementing them over longer periods of time. A tangible manifestation of this cautious approach to monetary policy is that the number of dissenting votes at Federal Open Market Committee (FOMC) meetings started to fall in the mid-1990's and has been very close to zero since 1997 (our regime shift date). ${ }^{3}$ The Federal Reserve also implemented a number of important measures to enhance transparency in the mid-1990s, such as more detailed FOMC meeting minutes, explicit announcement of a numerical target for the Federal Funds rate immediately after the meetings, and the release of detailed transcripts of FOMC meetings, albeit with a five-year delay.

Figure 1 suggests that changes in monetary policy are important for understanding changing bond risks. Changes in bond betas, shown in Panel A, line up closely with monetary policy breaks. Bond return volatility, shown in Panel B, also increases sharply at the first monetary policy break date, although there is also variation at other times, most notably a short-lived spike at the beginning of the middle subperiod. In contrast, oil price shocks do not line up closely with nominal bond betas. This observation suggests that changes in the volatility of supply shocks alone are insufficient to explain changes in bond risks. Oil price shocks represent only a subset of macroeconomic supply shocks and therefore the evidence in Figure 1 is merely suggestive. However, the main empirical analysis in this paper systematically examines the role of time-varying shock volatilities for nominal bond betas and

\footnotetext{
${ }^{3}$ Joshua Zumbrun, 2013, "Greenspan's Bequest to Yellen Is Board Harmony Shown in Records", Bloomberg News, November 6.
} 
corroborates this evidence.

This paper builds on the New Keynesian asset pricing literature and makes two contributions. First, we formulate a New Keynesian model in which bonds and stocks can both be priced from assumptions about their payoffs, and in which time-varying risk premia, driven by habit formation and stochastic volatility, generate realistic variances and covariances for these asset classes. Most previous New Keynesian asset pricing papers have concentrated on the term structure of interest rates, and have paid little attention to the implied pricing of equities. This contrasts with the integrated treatment of the bond and stock markets in several papers that use reduced-form affine or real business cycle models (Ang and Ulrich, 2012, Bansal and Shaliastovich 2013, Bekaert, Engstrom, and Grenadier 2010, Koijen, Lustig, and Van Nieuwerburgh, 2010, Campbell 1986, Campbell, Sunderam, and Viceira 2013, d'Addona and Kind 2006, Dew-Becker 2013, Eraker 2008, Hasseltoft 2008, Lettau and Wachter 2011, Wachter 2006).

Second, we use our model to relate changes in bond risks to periodic regime changes in the parameters of the central bank's monetary policy rule and the volatilities of macroeconomic shocks, including the regime shift that we newly identify in the late 1990s. In this way we contribute to the literature on monetary policy regime shifts (Andreasen 2012, Ang, Boivin, Dong, and Kung 2011, Bikbov and Chernov 2013, Boivin and Giannoni 2006, Chib, Kang, and Ramamurthy 2010, Clarida, Gali, and Gertler 1999, Palomino 2012, Rudebusch and $\mathrm{Wu}$ 2007, Smith and Taylor 2009). While this literature has begun to focus on the implications of monetary regime shifts for the term structure of interest rates, previous papers have not looked at the implications for the comovements of bonds and equities as we do here. Our structural analysis takes account of various channels by which the monetary 
policy regime affects the sensitivities of bond and stock returns to macroeconomic shocks, including endogenous responses of risk premia.

The organization of the paper is as follows. Section 2 lays out a basic New Keynesian model that explains interest rates, inflation, and medium-term deviations of output from trend (the "output gap") using three structural equations: an investment-saving curve (IS) that describes real equilibrium in the goods market based on the Euler equation of a representative consumer, a Phillips curve $(\mathrm{PC})$ that describes the effects of nominal frictions on inflation, and a monetary policy reaction function (MP) embodying a Taylor rule as in Clarida, Gali, and Gertler (1999), Taylor (1993), and Woodford (2001). This section also solves for the stochastic discount factor (SDF) implied by the New Keynesian IS curve, and uses it to price bonds and stocks.

Section 3 describes our data sources and presents summary statistics for our full sample period, 1960Q1 through 2011Q4, and for three subperiods, 1960Q1-1979Q2, 1979Q31996Q4, and 1997Q1-2011Q4. These subperiods are chosen to match both shifts in monetary policy and changes in measured bond risks. This section also estimates the parameters of the monetary policy reaction function, over the full sample and the three subperiods, using reduced-form regression methodology.

Section 4 calibrates our model to fit both macroeconomic and asset pricing data over our three subperiods. Section 5 presents counterfactual analysis, asking how bond risks would have evolved over time if the monetary policy rule, or the volatilities of macroeconomic shocks, had been stable instead of time-varying. Section 6 explores the implications of our model for inflation-indexed bonds. Section 7 concludes, and an online appendix (Campbell, Pflueger, and Viceira 2013) presents additional details. 


\section{A New Keynesian Asset Pricing Model}

We model the dynamics of macroeconomic time series with a standard New Keynesian framework consisting of a log-linearized Euler equation, a Phillips curve, and a monetary policy function. We integrate asset pricing into the framework by deriving the Euler equation from a stochastic discount factor (SDF) that also prices stocks and bonds in the model. The SDF links asset returns and macroeconomic and monetary variables in equilibrium.

The Euler equation is a standard New Keynesian building block and provides an equivalent of the Investment and Savings (IS) curve. We derive a micro-founded log-linearized Euler equation relating current output to the lagged output gap, the expected future output gap, and the real interest rate. Euler equations with both backward-looking and forwardlooking components are common in the dynamic stochastic general equilibrium (DSGE) literature (Christiano, Eichenbaum, and Evans 2005, Boivin and Giannoni 2006, Smets and Wouters 2007, Canova and Sala 2009). ${ }^{4}$ Fuhrer (2000) argues that allowing for a backwardlooking component is important for capturing the empirical hump-shaped output response to a monetary policy shock. The forward-looking component follows from standard household dynamic optimization.

We obtain an Euler equation with both backward-looking and forward-looking components from a consumption-based SDF in which the marginal utility of consumption depends on the current and lagged values of the output gap, and its conditional volatility varies inversely with the output gap. This assumption about the volatility of marginal utility implies

\footnotetext{
${ }^{4}$ Christiano, Eichenbaum, and Evans (2005) and Boivin and Giannoni (2006) derive a backward- and forward-looking linearized Euler equation in a model where utility depends on the difference between consumption and an internal habit stock. A backward-looking component in the Euler equation can also be derived in a model with multiplicative external habit (Abel 1990, Fuhrer 2000).
} 
that real risk premia increase during recessions, consistent with the empirical evidence on stock and bond return predictability (Chen 1991, Cochrane 2007, Cochrane and Piazzesi 2005, Fama 1990, Fama and French 1989, Lamont 1998, Lettau and Ludvigson 2001). A parametric model that exhibits these properties and produces analytically tractable expressions for asset prices and expected returns after suitable log-linearization of the SDF is the habit-formation model of Campbell and Cochrane (1999), in which utility is a power function of the difference between consumption and habit - the consumption surplus. We therefore adopt this specification of utility for analytical convenience. Finally, shocks to marginal utility, or demand shocks, introduce shocks to the Euler equation.

Figure 2, Panel A provides some empirical evidence to support our assumption that the marginal utility of consumption is a function of the current and lagged output gaps. This figure plots the time series of stochastically detrended consumption-log real consumption of nondurables and services less a 24-quarter moving average - and the log output gap. The two series move very closely together, almost surprisingly so given the measurement issues in both series, with a correlation of $90 \%$. We model surplus consumption to be linear in the current output gap and the lagged output gap, with a negative coefficient on the lag. We can therefore think of surplus consumption as a transformation of stochastically detrended consumption that accentuates higher-frequency movements.

The second building block of a New Keynesian model is the Phillips curve (PC) equation that links inflation and real output in equilibrium. We assume a PC with both forwardand backward-looking components to capture the price setting behavior of firms. While a Calvo (1983) model of monopolistically competitive firms and staggered price setting implies a forward-looking Phillips curve, a backward-looking Phillips curve can arise when price 
setters update their information infrequently (Mankiw and Reis 2002).

The third building block of the model is an equation describing the behavior of the central bank. We assume that the central bank's policy instrument is the short-term nominal interest rate. The central bank sets this interest rate according to a Taylor (1993) monetary policy (MP) rule, as a linear function of the "inflation gap" (the deviation of inflation from the central bank's target), the output gap, and the lagged nominal interest rate. Empirically, the Fed appears to smooth interest rates over time, and we capture this by modeling the nominal short rate as adjusting gradually to the target rate. This approach is fairly standard in the New Keynesian literature, although there is some debate over the relative importance of partial adjustment and serially correlated unobserved fundamentals in the MP rule (Rudebusch 2002, Coibion and Gorodnichenko 2012).

We allow for a time-varying central bank inflation target. Historical US inflation appears highly persistent (Ball and Cecchetti 1990, Stock and Watson 2007). We capture this empirical regularity by modeling the inflation target as a unit root process. ${ }^{5}$ Movements in our estimated inflation target may capture episodes where public expectations of central bank behavior are not well anchored, because the central bank lacks credibility, even if the central bank's true target is relatively stable (Orphanides and Williams 2004).

To close the model we need to make identification assumptions. Dynamic stochastic general equilibrium (DSGE) models are often under-identified or only very weakly identified (Canova and Sala 2009, An and Schorfheide 2007) because the mapping between underlying parameters and model moments can be highly nonlinear. Restrictions on the form of the

\footnotetext{
${ }^{5}$ We make this assumption for simplicity. We could alternatively model the inflation target as a stationary but persistent $\mathrm{AR}(1)$ process. These assumptions produce very similar results, except for the behavior of extremely long-term forward nominal interest rates. See also our discussion of bond price and return solutions.
} 
monetary policy shock may be necessary to identify monetary policy parameters (Backus, Chernov, and Zin 2013). We adopt identification assumptions commonly used in the structural vector autoregression literature to help identify the central bank's monetary policy rule, using exclusion restrictions that allow us to estimate the monetary policy rule by Ordinary Least Squares (OLS).

\subsection{Euler equation with habit formation}

Standard no-arbitrage conditions in asset pricing imply that the gross one-period real return $\left(1+R_{t+1}\right)$ on any asset satisfies

$$
1=\mathrm{E}_{t}\left[M_{t+1}\left(1+R_{t+1}\right)\right]
$$

where $M_{t+1}$ is the stochastic discount factor (SDF). Household optimization implies a SDF of the form

$$
M_{t+1}=\frac{\beta U_{t+1}^{\prime}}{U_{t}^{\prime}}
$$

where $U_{t}^{\prime}$ is the marginal utility of consumption at time $t$ and $\beta$ is a time discount factor. Substitution of (2) into (1) produces the standard Euler equation.

The Euler equation for the return on a one-period real T-bill can be written in log form as:

$$
\ln U_{t}^{\prime}=r_{t}+\ln \beta+\ln \mathrm{E}_{t} U_{t+1}^{\prime},
$$

where we write $r_{t}$ for the log yield at time $t$ - and return at time $t+1$ - on a one-period real Treasury bill. Similarly, we write $i_{t}$ to denote the log yield on a one-period nominal T-bill. 
We use the subscript $t$ for short-term nominal and real interest rates to emphasize that they are known at time t.

For simplicity, we assume that short-term nominal interest rates contain no risk premia or that $i_{t}=r_{t}+E_{t} \pi_{t+1}$, where $\pi_{t+1}$ is inflation from time $t$ to time $t+1$. This approximation is justified if uncertainty about inflation is small at the quarterly horizon, as appears to be the case empirically. Substituting $r_{t}=i_{t}-E_{t} \pi_{t+1}$ into (3), and dropping constants to reduce the notational burden, we have:

$$
\ln U_{t}^{\prime}=\left(i_{t}-\mathrm{E}_{t} \pi_{t+1}\right)+\ln \mathrm{E}_{t} U_{t+1}^{\prime} .
$$

We assume that $\ln U_{t}^{\prime}$ is a linear function of the current and lagged log output gap $x_{t}$ and that its conditional volatility is also an exponential affine function of $x_{t}$ with a negative slope so that the volatility of marginal utility is higher when the output gap is low. These assumptions imply an Euler equation for the real riskfree rate that relates the real interest rate to the current output gap, its first-order lag, and its expected value.

To see this, consider a habit formation model of the sort proposed by Campbell and Cochrane (1999), where utility is a power function of the difference between consumption $C$ and habit $H$ :

$$
U_{t}=\frac{\left(C_{t}-H_{t}\right)^{1-\alpha}-1}{1-\alpha}=\frac{\left(S_{t} C_{t}\right)^{1-\alpha}-1}{1-\alpha} .
$$

Here $S_{t}=\left(C_{t}-H_{t}\right) / C_{t}$ is the surplus consumption ratio and $\alpha$ is a curvature parameter that controls risk aversion. Relative risk aversion varies over time as an inverse function of the surplus consumption ratio: $-U_{C C} C / U_{C}=\alpha / S_{t}$. 
Marginal utility in this model is

$$
U_{t}^{\prime}=\left(C_{t}-H_{t}\right)^{-\alpha}=\left(S_{t} C_{t}\right)^{-\alpha},
$$

and $\log$ marginal utility is given by $\ln U_{t}^{\prime}=-\alpha\left(s_{t}+c_{t}\right)$. Assuming lognormality, or taking a second-order Taylor approximation, the Euler equation (4) becomes

$$
-\alpha\left(s_{t}+c_{t}\right)=\left(i_{t}-\mathrm{E}_{t} \pi_{t+1}\right)-\alpha \mathrm{E}_{t}\left(s_{t+1}+c_{t+1}\right)+\frac{\alpha^{2}}{2} \sigma_{t}^{2},
$$

where $\sigma_{t}^{2}=\operatorname{Var}_{t}\left(s_{t+1}+c_{t+1}\right)$.

Now suppose that

$$
s_{t}+c_{t}=x_{t}-\theta x_{t-1}-v_{t},
$$

where the error term $v_{t}$ is white noise uncorrelated with current or lagged $x_{t}$, or any other information variables known in advance. We have argued that the empirical output gap is closely related to stochastically detrended consumption, so the expression (8) can be interpreted as a simple transformation of stochastically detrended consumption. ${ }^{6}$

Furthermore, assume that the volatility of marginal utility is higher when the output gap is low. For some $0<b<1$ :

$$
\sigma_{t}^{2}=\bar{\sigma}^{2} \exp \left(-b x_{t}\right) \approx \bar{\sigma}^{2}\left(1-b x_{t}\right)
$$

\footnotetext{
${ }^{6}$ In the Campbell-Cochrane model, $s_{t}+c_{t}$ has a unit root to allow for long-term growth and persistent fluctuations in welfare. The Appendix describes an extended model, that adds a cointegrated random walk component to (8) and $\log$ dividends to reflect the nonstationarity of log consumption. The solution and calibration results are almost identical to the solution we present below. Adding a random walk component leads to only very modest increases the equity premium and equity volatility, reflecting the well known equity premium and equity volatility puzzles as reviewed in Campbell (2003).
} 
where $\bar{\sigma}$ is the conditional volatility of surplus consumption when the output gap is zero. The first-order linear approximation to volatility in (9) greatly facilitates finding an analytical solution to our model. Less appealingly, it also implies that conditional volatility can turn negative in discrete-time simulations. We note however that this problem will disappear as we shrink the time interval of the model, since other assumptions we make below ensure that the volatility of the output gap diminishes as it approaches the upper boundary $1 / b$ where the right-hand side of (9) would turn negative. In this respect our model is similar to Campbell and Cochrane (1999), who also have an upper bound on surplus consumption that can never be crossed in continuous time.

Substituting (8) and (9) into (7) yields the Euler equation:

$$
x_{t}=\rho^{x-} x_{t-1}+\rho^{x+} \mathrm{E}_{t} x_{t+1}-\psi\left(i_{t}-\mathrm{E}_{t} \pi_{t+1}\right)+u_{t}^{I S},
$$

where $\rho^{x-}=\theta /\left(1+\theta^{*}\right), \rho^{x+}=1 /\left(1+\theta^{*}\right), \psi=1 / \alpha\left(1+\theta^{*}\right), u_{t}^{I S}=v_{t} /\left(1+\theta^{*}\right)$, and $\theta^{*}=\theta-\alpha b \bar{\sigma}^{2} / 2<\theta$.

Several points are worth noting about the IS curve (10). First, because $\theta^{*}<\theta$, the coefficients on the lagged output gap and the expected future output gap sum to more than one. Second, the slope of the IS curve $\psi$ does not equal the elasticity of intertemporal substitution (EIS) of the representative consumer. Third, shocks to the IS curve result from marginal utility or demand shocks in equation (8). Alternatively, we can interpret these shocks as incorporating any divergences between consumption surplus and the output gap that are uncorrelated with the other shocks in the model. 


\subsection{Macroeconomic dynamics}

We complement the consumers' Euler equation with standard building blocks of New Keynesian macroeconomic models. We assume that consumers and price-setting firms do not incorporate contemporaneous monetary policy shocks into their time $t$ decisions, similarly to Christiano, Eichenbaum and Evans (2005). Instead, they form their time $t$ expectations based on monetary policy and inflation target shocks up to time $t-1$ and IS and PC shocks up to time $t$. We denote the expectation with respect to this information set by:

$$
\mathrm{E}_{t-}(\cdot)=\mathrm{E}\left(\cdot \mid u_{t}^{I S}, u_{t-1}^{I S}, u_{t-2}^{I S}, \ldots, u_{t}^{P C}, u_{t-1}^{P C}, u_{t-2}^{P C}, \ldots, u_{t-1}^{M P}, u_{t-2}^{M P}, u_{t-1}^{*}, u_{t-2}^{*}, \ldots\right)
$$

The assumption that consumers and firms make decisions based on $\mathrm{E}_{t-}$ expectations implies that monetary policy shocks and inflation target shocks do not affect macroeconomic aggregates contemporaneously, but only with a lag. This identification assumption is common in the structural VAR literature (Christiano, Eichenbaum, and Evans, 1999) and it is helpful for our empirical strategy in that we can estimate the monetary policy Taylor rule by OLS. Note that we do not assume the same lags for financial markets; we allow asset prices to react to monetary policy shocks contemporaneously.

The dynamics of the output gap, inflation, and Fed Funds rate are summarized by the 
following linearized system of equations:

$$
\begin{aligned}
x_{t} & =\rho^{x-} x_{t-1}+\rho^{x+} \mathrm{E}_{t-} x_{t+1}-\psi\left(\mathrm{E}_{t-} i_{t}-\mathrm{E}_{t-} \pi_{t+1}\right)+u_{t}^{I S}, \\
\pi_{t} & =\rho^{\pi} \pi_{t-1}+\left(1-\rho^{\pi}\right) \mathrm{E}_{t-} \pi_{t+1}+\lambda x_{t}+u_{t}^{P C}, \\
i_{t} & =\rho^{i}\left(i_{t-1}-\pi_{t-1}^{*}\right)+\left(1-\rho^{i}\right)\left[\gamma^{x} x_{t}+\gamma^{\pi}\left(\pi_{t}-\pi_{t}^{*}\right)\right]+\pi_{t}^{*}+u_{t}^{M P}, \\
\pi_{t}^{*} & =\pi_{t-1}^{*}+u_{t}^{*} .
\end{aligned}
$$

Equation (12) is the IS curve (10) with the expectational timing assumption (11).

Equation (13) is a standard New Keynesian equation that determines inflation from the price-setting behavior of firms. It has parameters $\rho^{\pi}$, determining the relative weight on past inflation and expected future inflation, and $\lambda$, governing the sensitivity of inflation to the output gap.

Equations (14) and (15) describe monetary policy. Equation (14) is a central bank reaction function along the lines of Clarida, Gali, and Gertler (1999), Taylor (1993), and Woodford (2001). It determines the short-term nominal interest rate with parameters $\rho^{i}$, controlling the influence of past interest rates on current interest rates, $\gamma^{x}$, governing the reaction of the interest rate to the output gap, and $\gamma^{\pi}$, governing the response of the interest rate to inflation relative to its target level $\pi_{t}^{*}$. Equation (15) specifies that the central bank's inflation target follows a random walk.

Monetary policy in our model does not react directly to long-term nominal bond yields or stock prices, but only to macroeconomic determinants of these asset prices. However, a persistent inflation target shifts the term structure similarly to a level factor. In that sense, our model is similar to models where the level factor of the nominal term structure directly 
enters the central bank's monetary policy function (Rudebusch and Wu 2007, 2008).

Finally, we assume that the vector of shocks

$$
u_{t}=\left[u_{t}^{I S}, u_{t}^{P C}, u_{t}^{M P}, u_{t}^{*}\right]^{\prime}
$$

is independently and conditionally normally distributed with mean zero and variance-covariance matrix:

$$
\mathrm{E}_{t-1}\left[u_{t} u_{t}^{\prime}\right]=\Sigma_{u} \times\left(1-b x_{t-1}\right)=\left[\begin{array}{cccc}
\left(\bar{\sigma}^{I S}\right)^{2} & 0 & 0 & 0 \\
0 & \left(\bar{\sigma}^{P C}\right)^{2} & 0 & 0 \\
0 & 0 & \left(\bar{\sigma}^{M P}\right)^{2} & 0 \\
0 & 0 & 0 & \left(\bar{\sigma}^{*}\right)^{2}
\end{array}\right] \times\left(1-b x_{t-1}\right)
$$

Equation (17) has two important properties. First, the variances of all shocks in the model, not just the shock to the Euler equation, are proportional to $\left(1-b x_{t-1}\right)$, and thus linear in the output gap. This proportionality or "affine stochastic volatility" assumption makes the model relatively tractable and helps us fit the volatilities of bond and stock returns. It also ensures that volatility always remains positive in a continuous-time version of the model. Second, for parsimony we assume that all the shocks in the model are uncorrelated with each other. The assumption that monetary policy shocks $u_{t}^{M P}$ and $u_{t}^{*}$ are uncorrelated with the $I S$ and $P C$ shocks captures the notion that all systematic variation in the short-term nominal interest rate is reflected in the monetary policy rule. 


\subsection{Modeling bonds and stocks}

We use the exact loglinear framework of Campbell and Ammer (1993) to express excess log returns on nominal and real bonds as a function of changes in expectations of future short-term interest rates, inflation, and risk premia. In our model, risk premia vary over time and the expectations hypothesis of the term structure of interest rates does not hold. We maintain our previous simplifying approximation that risk premia on one period nominal bonds equal zero, but risk premia on longer-term bonds are allowed to vary. We also assume that asset prices react contemporaneously to all shocks in the model, including monetary policy and inflation target shocks.

We write $r_{n-1, t+1}$ for the real one-period log return on a real n-period bond from time $\mathrm{t}$ to time $\mathrm{t}+1$ and $x r_{n-1, t+1}$ for the corresponding return in excess of $r_{t} \cdot r_{n-1, t+1}^{\$}$ denotes the nominal one-period return on a similar nominal bond and $x r_{n-1, t+1}^{\$}$ the corresponding excess return over $i_{t}$. We use the identities:

$$
\begin{aligned}
r_{n-1, t+1}^{\$}-\mathrm{E}_{t} r_{n-1, t+1}^{\$}= & -\left(\mathrm{E}_{t+1}-\mathrm{E}_{t}\right) \sum_{j=1}^{n-1}\left(\hat{\imath}_{t+j}+\pi_{t+j}^{*}\right) \\
& -\left(\mathrm{E}_{t+1}-\mathrm{E}_{t}\right) \sum_{j=1}^{n-1} x r_{n-j-1, t+1+j}^{\$} \\
r_{n-1, t+1}-\mathrm{E}_{t} r_{n-1, t+1}= & -\left(\mathrm{E}_{t+1}-\mathrm{E}_{t}\right) \sum_{j=1}^{n-1} r_{t+j} \\
& -\left(\mathrm{E}_{t+1}-\mathrm{E}_{t}\right) \sum_{j=1}^{n-1} x r_{n-j-1, t+1+j},
\end{aligned}
$$

Nominal bond excess returns reflect shocks to the long-term inflation target, news about the nominal interest rate gap, and news about future nominal bond excess returns. Real 
long-term excess bond returns reflect news about the real interest rate gap and news about future real bond excess returns.

We model stocks as a levered claim on the log output gap $x_{t}$. We assume that log dividends are given by:

$$
d_{t}=\delta x_{t} .
$$

We interpret $\delta$ as capturing a broad concept of leverage, including operational leverage. The interpretation of dividends as a levered claim on the underlying fundamental process is common in the asset pricing literature (Abel 1990, Campbell 1986, 2003).

We write $r_{t+1}^{e}$ for the log stock return and $x r_{t+1}^{e}$ for the log stock return in excess of $r_{t}$. Following Campbell (1991) we use a loglinear approximation to decompose stock returns into dividend news, news about real interest rates, and news about future excess stock returns ignoring constants:

$$
\begin{aligned}
r_{t+1}^{e}-E_{t} r_{t+1}^{e}= & \delta\left(\mathrm{E}_{t+1}-\mathrm{E}_{t}\right) \sum_{j=0}^{\infty} \rho^{j} \Delta x_{t+1+j}-\left(\mathrm{E}_{t+1}-\mathrm{E}_{t}\right) \sum_{j=1}^{\infty} \rho^{j} r_{t+j} \\
& -\left(\mathrm{E}_{t+1}-\mathrm{E}_{t}\right) \sum_{j=1}^{\infty} \rho^{j} x r_{t+1+j}^{e} .
\end{aligned}
$$

Here $\rho$ is a loglinearization constant close to 1 . 


\subsection{Model solution and stability}

We define the inflation and nominal interest rate gaps as:

$$
\begin{aligned}
& \hat{\pi}_{t}=\pi_{t}-\pi_{t}^{*}, \\
& \hat{\imath}_{t}=i_{t}-\pi_{t}^{*} .
\end{aligned}
$$

We solve for the dynamics of the vector of state variables

$$
\hat{Y}_{t}=\left[x_{t}, \hat{\pi}_{t}, \hat{\imath}_{t}\right]^{\prime}
$$

The state variable dynamics have a solution of the form

$$
\hat{Y}_{t}=P \hat{Y}_{t-1}+Q u_{t}
$$

We solve for $P \in \mathbb{R}^{3 \times 3}$ and $Q \in \mathbb{R}^{3 \times 4}$ using the method of generalized eigenvectors (see e.g. Uhlig 1999).

In principle, the model can have more than one solution. We only consider dynamically stable solutions with all eigenvalues of $P$ less than one in absolute value, yielding nonexplosive solutions for the output gap, inflation gap, and interest rate gap. Cochrane (2011) argues that there is no economic rationale for ruling out solutions on the basis of an explosive inflation path. In general, in our model an explosive solution for inflation is also explosive for the output gap and the real interest rate. We find it reasonable to rule out such solutions with explosive real dynamics.

The inclusion of backward-looking terms in the IS curve and Phillips curve means that 
there exist at most a finite number of dynamically stable equilibria of the form (25). This is true even when the monetary policy reaction to inflation $\left(\gamma^{\pi}\right)$ is smaller than one, which usually leads to an indeterminate equilibrium in highly stylized Keynesian models with only forward-looking components (Cochrane, 2011).

Next we apply multiple equilibrium selection criteria proposed in the literature to rule out unreasonable solutions and pick a unique solution. We require the solution to be realvalued and "expectationally stable" (Evans 1985, 1986, McCallum 2003). Expectational stability requires that for small deviations from rational expectations, the system returns to the equilibrium. We also impose the solution selection criterion of Uhlig (1999), which is closely related to the minimum state variable solution proposed by McCallum (2004).

While we formally model regimes as lasting an infinite period of time, one might think that agents understand that the regime will have to end eventually, potentially arbitrarily far into the future. We implement the Cho and Moreno (2011) criterion, which captures this limiting case. This criterion, also used by Bikbov and Chernov (2013), has two appealing interpretations. The first interpretation is closely linked to a possibility that the regime will switch back to a stable equilibrium in the distant future. The Cho and Moreno (2011) criterion is equivalent to assuming that the system returns to an equilibrium with all variables constant from period $\tau$ onwards and then letting $\tau$ go to infinity. ${ }^{7}$ An alternative interpretation of the Cho and Moreno (2011) criterion is closely related to expectational stability. If agents deviate from rational expectations and instead have constant expectations, the system returns to the Cho and Moreno (2011) equilibrium. The Appendix provides full details on the model solution and solution criteria.

\footnotetext{
${ }^{7}$ We thank Mikhail Chernov for pointing out to us that when rational agents anticipate a return to a different equilibrium, even regimes with an inflation reaction coefficient less than one can have a determinate equilibrium.
} 


\subsubsection{Stochastic discount factor}

We can express innovations to log consumption plus habit as:

$$
\begin{aligned}
s_{t+1}+c_{t+1}-E_{t}\left(s_{t+1}+c_{t+1}\right) & =Q^{M} u_{t+1}, \\
Q^{M} & =e_{1} Q-\left(1+\theta^{*}\right) e_{1},
\end{aligned}
$$

where $e_{1}$ is a vector with first element one and all other elements zero. In (9) we assumed that the conditional variance of the log SDF is linear in the output gap. Using equation (17) for the changing variance of the shock vector $u_{t+1}$, we can now verify this assumption with:

$$
\sigma_{t}^{2}=Q^{M} \Sigma_{u} Q^{M \prime}\left(1-b x_{t}\right)
$$

The variance of the SDF conditional on a zero output gap is $\bar{\sigma}^{2}=Q^{M} \Sigma_{u} Q^{M \prime}$.

\subsubsection{Solutions for bond and stock returns}

We obtain solutions for unexpected nominal and real bond returns of the form:

$$
\begin{aligned}
& r_{n-1, t+1}^{\$}-E_{t} r_{n-1, t+1}^{\$}=A^{\$, n} u_{t+1}, \\
& r_{n-1, t+1}-E_{t} r_{n-1, t+1}=A^{n} u_{t+1} .
\end{aligned}
$$

Expected log excess nominal and real bond returns take the following form:

$$
\begin{aligned}
& E_{t} x r_{n-1, t+1}^{\$}=\left(1-b x_{t}\right) b^{\$, n} \\
& E_{t} x r_{n-1, t+1}=\left(1-b x_{t}\right) b^{n} .
\end{aligned}
$$


Up to constant terms, log yields of nominal and real zero coupon bonds equal:

$$
\begin{aligned}
& y_{n, t}^{\$}=\pi_{t}^{*}+B^{\$, n} \hat{Y}_{t}, \\
& y_{n, t}=B^{n} \hat{Y}_{t} .
\end{aligned}
$$

The loglinear decompositions (18) and (19) for nominal and real bonds are exact, so the solutions for model bond returns and yields (29)-(34) are also exact, conditional on our $\log$ linearization of the stochastic discount factor. The vectors $A^{\$, n} \in \mathbb{R}^{1 \times 4}, A^{n} \in \mathbb{R}^{1 \times 4}$, $B^{\$, n} \in \mathbb{R}^{1 \times 3}$, and $B^{n} \in \mathbb{R}^{1 \times 3}$ are defined recursively.

Unexpected and expected log excess stock returns take the following loglinear approximate forms:

$$
\begin{aligned}
r_{t+1}^{e}-E_{t} r_{t+1}^{e} & =A^{e} u_{t+1}, \\
E_{t} x r_{t+1}^{e} & =\left(1-b x_{t}\right) b^{e},
\end{aligned}
$$

for some $A^{e} \in \mathbb{R}^{1 \times 4}$ and some $b^{e} \in \mathbb{R}$. The online Appendix presents solution details, including bond betas, log dividend price ratios, and multi-period expected log equity returns in excess of short-term T-bills.

The solutions for unexpected and expected bond and stock returns imply that both the first and second conditional moments of asset returns vary over time with the output gap. This variation gives our model two important non-linear properties.

First, time-varying risk premia generate a non-linear effect of fundamental shocks on bond betas which can amplify their linear effect. For example, consider a contractionary 
shock that simultaneously lowers output and inflation. The shock pushes stock valuations lower but nominal bond prices higher, generating a negative nominal bond beta. But the negative bond beta implies that nominal bonds are safe assets that hedge equity risk, thus appealing to risk averse investors. Since risk aversion is countercyclical in our model, the recessionary shock makes bonds even more appealing to investors, which pushes bond risk premia lower and bond prices even higher, amplifying the effect of the shock on bond beta. We show in our empirical calibration of the model that amplification mechanisms of this kind, operating through time-varying risk premia, can be quantitatively important.

Second, it is well known that yield volatility induces a positive Jensen's Inequality or convexity effect on bond prices. Because bonds have positive convexity, large declines in yields increase bond prices more than equally large increases in yields reduce them. Anticipating this, investors in equilibrium pay more for bonds when yield volatility is high. In our model, volatility increases in recessions and falls in expansions, so the convexity effect pushes bond prices higher in recessions, lowering the bond beta. Furthermore, because the convexity effect is stronger for bonds of higher convexity, and bond convexity increases as yields fall, the negative impact on bond betas is larger for fundamental shocks that also push yields lower in recessions. Because our model has a state variable (the inflation target) with a unit root, the convexity effect increases with maturity and has no finite limit, implying that very long-term forward rates turn negative in our model.

However, the Appendix shows that the convexity term makes only a very small contribution to bond betas at the maturities considered. The Appendix shows that the decomposition of changes in bond betas is essentially unchanged if we ignore the convexity term in bond prices. 


\subsubsection{An estimable VAR}

While standard empirical measures are available for the output gap, we do not observe the interest rate and inflation gaps. We therefore cannot directly estimate the recursive law of motion (25). However, for a long-term bond maturity $n$, we can estimate a $\operatorname{VAR}(1)$ in the vector:

$$
Y_{t}=\left[x_{t}, \pi_{t}, i_{t}, y_{n, t}^{\$}\right]^{\prime}
$$

The model implies that:

$$
Y_{t+1}=P^{Y} Y_{t}+Q^{Y} u_{t+1}^{Y}
$$

Here, $u_{t}^{Y}=u_{t}$ and $P^{Y}$ and $Q^{Y}$ are determined by $P, Q$ and the loadings for long-term nominal bond yields $B^{\$, n}$.

\section{Preliminary Empirical Analysis}

\subsection{Monetary policy regimes}

We break our sample into three subperiods corresponding to major shifts in monetary policy. The first subperiod, 1960.Q1-1979.Q2, covers the Fed chairmanships of William M. Martin, Arthur Burns, and G. William Miller. The second subperiod, 1979.Q3-1996.Q4, covers the Fed chairmanships of Paul Volcker and Alan Greenspan. The third subperiod, 1997.Q1-2011.Q4, covers the period after Alan Greenspan's "Central Banking in a Democratic Society" speech at the end of 1996.Q4 (Greenspan 1996). The third period contains the 
later part of Greenspan's chairmanship and the earlier part of Ben Bernanke's chairmanship.

Our first two subperiods are identical to those considered by Clarida, Gali, and Gertler (CGG, 1999), while our third covers data that has become available since. Following CGG, we assume that transitions from one regime to another are structural breaks, completely unanticipated by investors. This approach is motivated by the empirical observation that regimes in the nominal bond beta and monetary policy regimes are typically long-lasting on the order of one to two decades. While we recognize the importance of allowing agents to anticipate potential future changes in policy and to optimize according to such expectations, we think that a parsimonious model like ours still brings substantive insights which are likely to survive in a more sophisticated but less analytically tractable model.

Our choice of a third regime for monetary policy draws on several observations. First, in 1994 the Fed started to announce FOMC decisions and to publish more detailed minutes of FOMC meetings. Observers of the Federal Reserve have noted that this increased transparency opened Fed deliberations to intense scrutiny by investors and the public. Consequently, increased transparency may have led to changes in the conduct of monetary policy towards more gradualism, with the central bank deciding on smaller interest rate changes, adopting more cautious policies, and implementing them over longer time horizons.

Second, Federal Reserve governors and chairmen have repeatedly noted a sense of increased uncertainty about the effects of monetary policy since the mid-1990s. Anecdotal evidence suggests that this led the Federal Reserve to adopt a more gradualist monetary policy (Greenspan 1996, Bernanke 2004, Orphanides 2003). ${ }^{8}$

\footnotetext{
${ }^{8}$ Greenspan (1996): "At different times in our history a varying set of simple indicators seemed successfully to summarize the state of monetary policy and its relationship to the economy. (...) Unfortunately, money supply trends veered off path several years ago as a useful summary of the overall economy." Bernanke (2004): "As a general rule, the Federal Reserve tends to adjust interest rates incrementally, in a series of
} 
Third, the experience of moderate inflation and apparently well anchored inflation expectations from the mid-1980s through the mid-1990s seems to have encouraged the Federal Reserve to turn its attention back to output stabilization, after the single-minded focus on combating inflation under Fed chairman Paul Volcker. Observers of the Federal Reserve have interpreted Greenspan's 1996 speech as a signal of increased central bank concern with capital market conditions, and specifically the level of stock prices. However Greenspan (1996) argues that "central bankers do not need to be concerned if a collapsing asset bubble does not threaten to impair the real economy." We therefore find it natural to interpret the speech as evidence for concern with output, consistent with our monetary policy rule that incorporates asset prices only to the extent that they reflect inflation and output fluctuations. The empirical evidence in Rigobon and Sack (2003) is also consistent with this interpretation.

Finally, Figure 1 in the introduction shows that substantial changes in the sign and magnitude of nominal bond betas and bond return volatilities line up reasonably well with our proposed monetary policy regimes. Our estimates of the monetary policy rule shown below also provide robust empirical support for the existence of a third monetary policy regime.

\subsection{Data and summary statistics}

Our empirical analysis uses quarterly US data on output, inflation, interest rates, and aggregate bond and stock returns from 1960.Q1 to 2011.Q4. GDP in 2005 chained dollars and

small or moderate steps in the same direction. (...) Many central bankers and researchers have pointed to the pervasive uncertainty associated with analyzing and forecasting the economy as a reason for central bank caution in adjusting policy." See also the analysis in Stein (2013). 
the GDP deflator are from the Bureau of Economic Analysis via the Fred database at the St. Louis Federal Reserve. The end-of-quarter Federal Funds rate is from the Federal Reserve's H.15 publication. We use quarterly potential GDP in 2005 chained dollars from the Congressional Budget Office. ${ }^{9}$ The end-of-quarter three-month T-bill is from the CRSP monthly Treasury Fama risk free rates files. We use log yields based on average of bid and ask quotes. The end-of-quarter five year bond yield is from the CRSP monthly Treasury Fama-Bliss discount bond yields. We use the value-weighted combined NYSE/AMEX/Nasdaq stock return including dividends from CRSP, and measure the dividend-price ratio using data for real dividends and the S\&P 500 real price. ${ }^{10}$ Interest rates, and inflation are in annualized percent, while the log output gap is in natural percent units. All yields are continuously compounded. We consider log returns in excess of the log T-bill rate.

Table 1 shows summary statistics for the log output gap, inflation, the Federal Funds rate, and the 5-year nominal bond yield for the US over the full sample period 1960-2011 and over each subperiod. The log real output gap has a first-order quarterly autocorrelation of 0.96 over the full sample period, implying a half life of 5 years. Realized inflation, the Fed Funds rate and the 5-year nominal bond yield are also highly persistent in the full sample and across subperiods. The average log output gap was positive in the earliest subperiod, and negative afterwards. Inflation and interest rates have been significantly lower in the latest subperiod compared to the early subperiods.

In our model, expected excess log stock returns vary negatively with the output gap. We now verify empirically that this relation exists, and examine the relation of the output gap with well known predictors of excess stock returns in the data such as the price-dividend

\footnotetext{
${ }^{9}$ Table 2-3 of the CBO's August 2012 report "An Update to the Budget and Economic Outlook: Fiscal Years 2012 to 2022" (http://www.cbo.gov/publication/43541)

${ }^{10}$ The source is Robert Shiller's website at http://www.econ.yale.edu/ shiller/data.htm.
} 
ratio.

Figure 2, Panel B shows the log output gap and the log price-dividend ratio for the full sample period. The correlation between the two variables in Figure 3 is 0.18 for the full sample period, but it is 0.39 for 1960.Q1-1979.Q3, 0.41 for 1979.Q3-1996.Q4, and 0.74 for 1997.Q1-2011.Q4. The procyclicality of the price-dividend ratio is evident in Figure 2. Occasional long-lasting shifts in the relative levels of the two variables, particularly the secular increase in the price-dividend ratio during the bull market at the end of the 20th Century, decrease the full sample correlation relative to the subsample correlations.

Time-varying volatilities of shocks imply that the equity premium in our model varies inversely with the output gap. We wish to compare time-variation in empirical and model risk premia. Table 2 estimates the predictive relation between quarterly equity excess returns and the output gap:

$$
r_{t+1}^{e}-i_{t}=a^{0}+a^{x} x_{t}+\epsilon_{t+1}
$$

Table 2 shows that the full sample estimate of $a^{x}$ is negative and significant, consistent with our model specification. Subsample estimates vary around the full sample estimate of $a^{x}=-0.49$.

We also consider the log dividend-price ratio (the negative of the log price-dividend ratio) as a predictor of equity excess returns. Table 3 reports regressions of one through five year log equity excess returns onto the lagged log dividend-price ratio. We report regressions over our full sample period 1960-2011 and an extended sample period 1947-2011. Table 3 shows that the log dividend-price ratio predicts equity excess returns with positive coefficients. The coefficients in Table 3 are comparable to those reported in Campbell and Cochrane (1999), but smaller in magnitude due to our inclusion of more recent data. 


\subsection{Estimating monetary policy rules}

The central bank's Taylor rule parameters are key inputs for calibrating the model for each subperiod. The model incorporates exclusion restrictions, such that if we knew the output gap, the inflation gap, and the interest rate gap we could estimate the monetary policy function by OLS. Unfortunately, the inflation gap and interest rate gap are not directly observable. We therefore follow CGG in estimating the monetary policy rule in terms of the output gap, inflation, and the Fed Funds rate:

$$
i_{t}=c^{0}+c^{x} x_{t}+c^{\pi} \pi_{t}+c^{i} i_{t-1}+\epsilon_{t} .
$$

We use the estimated values $\hat{c}^{x}, \hat{c}^{\pi}$, and $\hat{c}^{i}$ to pin down the calibrated values of the monetary policy parameters according to: $\hat{\rho}^{i}=\hat{c}^{i}, \hat{\gamma}^{x}=\hat{c}^{x} /\left(1-\hat{c}^{i}\right)$, and $\hat{\gamma}^{\pi}=\hat{c}^{\pi} /\left(1-\hat{c}^{i}\right)$. Table 4 reports standard errors for these parameters using the delta method, and indicates with stars the parameters that are significant at the $5 \%$ or $1 \%$ level based on a likelihood ratio test.

The estimated monetary policy functions in Table 4 yield consistent estimates of the monetary policy parameters only if the inflation target is constant or contemporaneously uncorrelated with the output gap and inflation gaps. We will therefore need to verify that this bias is quantitatively small in the calibrated model.

The estimates in Table 4 suggest that monetary policy has varied substantially over time. During the earliest subperiod, 1960.Q1-1979.Q2, the central bank raised nominal interest rates less than one-for-one with inflation. In contrast, the central bank raised nominal interest rates more than one-for-one with inflation during the both the later two subperiods 
(1979.Q3-2011.Q4). ${ }^{11}$ This finding is consistent with the empirical evidence reported by CGG and updates it to the most recent period.

The point estimates of $\hat{\gamma}^{x}$ in Table 4 also suggest that the central bank has put somewhat higher weight on output fluctuations in the earliest and latest subperiods than during the middle subperiod, although the estimates of neither $\hat{\gamma}^{x}$ nor $\hat{c}^{x}$ are statistically significant in the latest subperiod. This empirical finding is similar to Hamilton, Pruitt, and Borger (2011) who use the reaction of Fed Funds futures to macroeconomic announcements to estimate monetary policy rules before and after 2000 .

Consistent with our informal observations about increased gradualism in monetary policy, during the most recent subperiod the regression explains $91 \%$ of the variation in the Federal Funds rate, implying only small deviations from the monetary policy rule. The coefficient on the lagged Fed Funds rate in the monetary policy function is very large at 0.89 , almost twice the value in the earlier subperiods. We will see that this increase in estimated policy persistence is important for understanding changing bond risks.

Our findings for the third subperiod are not driven by the onset of the global financial crisis or the subsequently binding zero lower bound for the nominal interest rate. The Appendix estimates monetary policy rules for two parts of the third subperiod, before and after the start of the financial crisis, which we take to be the third quarter of 2008 . Not surprisingly, none of the estimated coefficients of the monetary policy rule are statistically different from zero during the post-crisis period. But the pre-crisis period still shows very strong persistence in monetary policy.

\footnotetext{
${ }^{11} \hat{\gamma}^{\pi}$ appears to be less precisely estimated in the latest subperiod, while $\hat{c}^{\pi}$ is precisely estimated. This results from the nonlinear relation between the parameters. The coefficient $\hat{\gamma}^{\pi}$ is $\hat{c}^{\pi}$ divided by $\left(1-\hat{c}^{i}\right)$. Because $\hat{c}^{i}$ is very close to 1 in the latest subperiod, standard errors for $\hat{\gamma}^{\pi}$ based on the delta method tend to be very large.
} 


\section{Model Calibration}

We now calibrate our model to key empirical moments for the US over the three subsamples: 1960.Q1-1979.Q2, 1979.Q3-1996.Q4, and 1997.Q1-2011.Q4. Table 5 summarizes the calibration parameters, while Tables 6 and 7 compare key empirical and model moments.

\subsection{Calibration procedure}

We separate the parameters into two blocks. The first block of parameters corresponds to our main candidate explanations for changes in bond betas. It comprises the monetary policy rule parameters $\gamma^{x}, \gamma^{\pi}$, and $\rho^{i}$ and the shock volatilities $\bar{\sigma}^{I S}, \bar{\sigma}^{P C}, \bar{\sigma}^{M P}$, and $\bar{\sigma}^{*}$. We allow these parameters to change over time. The second block of time-invariant parameters comprises the preference parameters and the Phillips curve parameters $\left(\rho, \delta, \alpha, b, \theta, \rho^{\pi}\right.$, and ג). Our selection of parameter blocks is consistent with Smets and Wouters (2007), who estimate a structural New Keynesian model separately for the periods 1966-1979 and 19842004. They find important changes the shock volatilities and the monetary policy parameters across those two periods, whereas estimated preference parameters are largely stable across subperiods.

We calibrate the monetary policy parameters $\rho^{i}, \gamma^{x}$, and $\gamma^{\pi}$, the leverage parameter $\delta$, and the loglinearization parameter $\rho$ to previous empirical evidence. We use the empirical evidence in Table 4 to pin down the monetary policy parameters for the three subperiods. Over the full sample period the standard deviations of four quarter real dividend growth and four quarter output gap growth are $5.35 \%$ and $2.20 \%$. The ratio of these empirical standard deviations pins down the model leverage parameter at $\delta=2.43$, corresponding to a leverage 
ratio of $59 \%$. We interpret $\delta$ as capturing a broad concept of leverage, including operational leverage. We choose the loglinearization parameter $\rho$ as in Campbell and Ammer (1993), scaled to quarterly frequency.

All other parameters $\left\{\alpha, b, \theta, \rho^{\pi}, \lambda, \sigma^{I S, p}, \sigma^{P C, p}, \sigma^{M P, p}, \sigma^{*, p}: p=1,2,3\right\}$ are chosen to minimize the distance between model and empirical moments, where $p$ denotes subperiod parameters. We fit the slope coefficients of a $\operatorname{VAR}(1)$ in the log output gap, log inflation, the log Fed Funds rate, and the five year nominal log bond yield. We also fit the standard deviations of the VAR(1) residuals, equity return volatility and bond return volatility and the nominal bond beta. ${ }^{12}$

The curvature parameter $\alpha$ is one of the main parameters that determine the volatility of equity returns and the unconditional equity premium. Our model generates a reasonable average unconditional annualized risk premium of $4.71 \%$, even though our procedure does not explicitly match the equity premium. The optimization procedure yields $\theta=\rho^{x-} / \rho^{x+}=0.50$, so investors' habit moves less than one for one with the lagged output gap.

The heteroskedasticity parameter $b$ determines time-varying risk premia and is an important determinant of bond and stock returns volatility. Table 7 verifies that the model matches empirical stock return predictability from the output gap, indicating that our choice of $b$ captures empirically plausible time-varying risk premia. Our model is formulated in discrete time and consequently the expression for the conditional variance factor $\left(1-b x_{t}\right)$ can turn negative. If we were to shrink the time interval and go to the continuous-time limit,

\footnotetext{
${ }^{12}$ The objective function is the sum of squared differences between model and empirical moments summed over all three sub-periods. The equity and bond volatilities are scaled by 0.1 and the nominal bond beta is scaled by a factor of 10 to ensure that moments have roughly equal magnitudes. For computational tractability we first minimize the objective function while holding $\alpha$ and $b$ fixed and then minimize over $\alpha$ and $b$ while holding all other parameters constant. The Appendix gives details of the optimization procedure.
} 
the resulting affine stochastic volatility model would have strictly positive conditional variances. However, the output gap would be bounded above by $1 / b=1.37 \%$ in excess of its unconditional mean.

Our optimization procedure yields a Phillips curve slope of $\lambda=0.04$. Rotemberg and Woodford (1997) and Woodford (2003) obtain a similarly small Phillips curve slope in a microfounded New-Keynesian model where prices on average remain constant for three quarters. ${ }^{13}$ The optimization procedure gives rise to a strongly backward-looking Phillips curve with $\rho^{\pi}=0.96$, which helps us generate large and empirically plausible persistence in the output gap and dividend yields. A strongly backward-looking Phillips curve is consistent with empirical evidence by Fuhrer (1997) and can arise in a model with infrequent information updating (Mankiw and Reis, 2002). Gali and Gertler (1999) find some empirical evidence in favor of a forward-looking curve using the labor share of income instead of the output gap.

The standard deviations of shocks, evaluated at a zero value of the output gap, change considerably and intuitively across time periods. We estimate a substantially larger volatility of MP shocks for the period 1979-1996 than for the earliest subperiod and especially the latest subperiod. A substantially larger volatility of inflation target shocks in the second and third subperiods mirrors the increased volatility of bond yield surprises. The estimated volatility of PC shocks is largest in the earliest subperiod, a period comprising major global oil price shocks. The estimated volatility of IS shocks is the smallest of all shock volatilities, and it stays roughly constant across subperiods.

Table 5, Panel B shows the values of calibration parameters that are implied by the

\footnotetext{
${ }^{13}$ CGG note that values in the literature range from 0.05 (Taylor 1980) to values as large as 1.2. A small Phillips curve slope helps us generate empirically plausible persistence in the output gap.
} 
parameters shown in Panel A. The calibrated Euler equation has economically significant forward-looking and backward-looking components with a backward-looking component of 0.34 and a forward-looking component of 0.68. The forward- and backward-looking Euler equation components sum to more than one as a result of time-varying risk premia. In principle, the Euler equation coefficients can vary across subperiods. However, in our calibration this variation is quantitatively small. The implied slope of the IS curve with respect to the real interest rate equals $\psi=0.04$ for each subperiod. A small value for the slope of the Euler equation helps generate persistence in the output gap, inflation, and the Fed Funds rate and is in line with the empirical findings in Yogo (2004) and earlier work by Hall (1988). ${ }^{14}$

\subsection{Evaluating the fit of the model}

Table 6 shows calibrated and empirical volatilities of VAR(1) residuals, volatilities of stock and bond returns, nominal bond betas, and Taylor rule regressions of the same form as in Table 4. Model moments are calculated from 2000 simulations of length 250, corresponding closely to our empirical sample size of 61 years of quarterly observations.

The calibrated model generally provides a close fit for the standard deviations of VAR(1) residuals for each of the subperiods, although it understates the volatility of inflation shocks in the second and third subperiods, and the volatility of long-term nominal bond yield shocks in the second subperiod.

The calibrated model also provides a close fit of the stock and bond return volatilities in the first and third subperiods, although it tends to somewhat overstate stock return volatility

\footnotetext{
${ }^{14}$ However the long-run risk literature, following Bansal and Yaron (2004), presents an opposing view.
} 
and to understate bond return volatility in the first two subperiods. The calibrated model fits very well the time variation in the nominal bond beta across subperiods. Both empirical and model nominal bond betas were small but positive in the first subperiod, larger and positive in the second subperiod, and negative during the third subperiod. These changes in bond risks are the primary object of interest in our analysis.

The model's simulated Taylor rules also correspond quite well to their empirical counterparts for each subperiod. This finding is reassuring in that it suggests that we can indeed identify time-varying monetary policy parameters from the regressions reported in Table 4 even without estimating the unobservable inflation target.

Our calibration generates additional model moments not used in the fitting procedure that can be used to evaluate the model's out-of-sample performance. Table 7 shows that many of these moments are comparable to their empirical counterparts. The model generates empirically plausible persistence in the output gap with a quarterly autoregressive coefficient of 0.97 . The model closely matches the slope coefficient of equity excess returns onto the lagged output gap, which we estimated in Table 2. This slope parameter is closely linked to the heteroskedasticity parameter $b$ in the model, supporting our choice of $b$.

The calibration generates a positive and plausible correlation between the output gap and the log price-dividend ratio, especially given that empirical subperiod correlations between these two variables tend to exceed full sample correlations. The log dividend-price ratio is persistent, but less persistent and less volatile than in the data. In the model, the output gap and log dividend-price ratio both predict stock excess returns with the right signs. However, the model generates stronger return predictability from the log dividend-price ratio than one can estimate in the data. All these findings are consistent with the view that in the data, 
some long-run force not captured by our model drove up stock prices in the late 20th Century, reducing the full-sample empirical correlation between the log price-dividend ratio and the output gap, reducing the predictability of stock returns, and increasing the persistence of the log price-dividend ratio.

Table 7 also reports the average standard deviation of the real interest rate in the model, which is a reasonable $2.36 \%$ per annum. The coefficient from regressing $s_{t}+c_{t}$ onto the output gap $x_{t}$ is positive, consistent with the intuition that marginal utility should be low when the output gap is high.

\section{Counterfactual Analysis of Changing Bond Risks}

We are now in a position to investigate the role of changing monetary policy and macroeconomic shocks for nominal bond betas. Our calibrated model replicates the shift in nominal bond betas over time. Since we allow both monetary policy and the volatilities of shocks to vary across subperiods, both may contribute to time-varying bond risks to varying degrees.

\subsection{Monetary policy coefficients and nominal bond betas}

Figure 3 plots nominal bond betas against the monetary policy reaction coefficients $\gamma^{x}$ and $\gamma^{\pi} \cdot \gamma^{\pi}$ captures the long-run response of monetary policy to an increase in the inflation gap, while $\gamma^{x}$ captures the response to an increase in the output gap. Each panel corresponds to one subperiod. The following parameters vary across panels and equal the calibration values

for the respective subperiod: the persistence of monetary policy $\rho^{i}$, and the volatilities of 
shocks $\bar{\sigma}^{I S}, \bar{\sigma}^{P C}, \bar{\sigma}^{M P}$, and $\bar{\sigma}^{*}$. Red and orange colors indicate positive bond betas, while blue and green colors indicate negative bond betas. White areas indicate that no stable solution exists. We show the estimated combinations of monetary policy parameters for each subperiod as a diamond (first subperiod), circle (second subperiod), and square (third subperiod), linked by arrows indicating the parameter changes at each regime change.

The contour lines in Figure 3 show combinations of reaction coefficients $\gamma^{x}$ and $\gamma^{\pi}$ that keep bond betas fixed. These contours are upward-sloping in all three panels, showing that $\gamma^{\pi}$ increases the bond beta while $\gamma^{x}$ reduces it. However, the contours shift across Panels A through $\mathrm{C}$, indicating that changes in parameters other than $\gamma^{x}$ and $\gamma^{\pi}$ are important for matching changes in bond betas.

Turning to specific results for our three subsamples, Figure 3, Panel A shows that nominal bond betas are positive for a wide range of monetary policy reaction coefficients $\gamma^{x}$ and $\gamma^{\pi}$ in the presence of period 1 shock volatilities and period 1 monetary policy persistence. A monetary policy rule with a higher weight on stabilizing inflation $\gamma^{\pi}$, such as those estimated for our second and third subsamples, would have produced even more positive bond betas than were actually observed during 1960.Q1-1979.Q2.

Panel B shows that in the presence of period 2 shocks and monetary policy persistence, the sign of the nominal bond beta is highly sensitive to the central bank's weight on inflation stabilization $\gamma^{\pi}$ and output $\gamma^{x}$. The slope of the contour lines is steeper in this superiod than in subperiod 1 and very close to the 45 degree line. The central bank's strong emphasis on inflation stabilization and small concern with output stabilization during 1979.Q3-1996.Q4 is reflected in the strongly positive nominal bond beta during this period.

Panel C indicates that the negative nominal bond beta since the late 1990s can partly 
be attributed to the increase in the monetary policy reaction coefficient $\gamma^{x}$. The slope of the contour lines is again steeper than in subperiod 1. In the presence of period 3 shock volatilities and period 3 monetary policy persistence, the nominal bond beta would have been close to zero rather than clearly negative if the weights on output and inflation stabilization, $\gamma^{x}$ and $\gamma^{\pi}$, had remained constant between periods 2 and 3 . It would have been even more negative than actually observed if monetary reaction coefficients in period 3 had been those measured for period 1 .

In Figure 4 we replace the output reaction coefficient $\gamma^{x}$ with the monetary persistence parameter $\rho^{i}$, plotting nominal bond betas against the monetary policy parameters $\gamma^{\pi}$ and $\rho^{i}$. In Panel A the contour lines are flat, but in Panel B and especially in Panel C they are upward-sloping and convex, becoming extremely steep as monetary persistence approaches its maximum value of one. This shows that $\gamma^{\pi}$ increases the bond beta while $\rho^{i}$ reduces it for the two most recent regimes, and $\rho^{i}$ has a nonlinear effect that is stronger at high levels of persistence. This is important given the increase in persistence we have estimated for our final subperiod.

Figure 4, Panel $\mathrm{C}$ indicates that strong monetary policy persistence during the most recent subperiod has helped generate a strongly negative nominal bond beta. Moreover, a move to third-period monetary policy persistence would have acted to decrease the nominal bond beta in the presence of 1979.Q3-1996.Q4 shock volatilities and output gap reaction coefficient $\gamma^{x}$.

We can also use Figures 3 and 4 to understand the implications of the model for nominal bond betas when the nominal interest rate approaches the zero lower bound. Given the other parameters of the model that we have calibrated, no model solution may exist for 
zero values of all monetary policy parameters simultaneously. However, the figures indicate that bond betas tend to be negative when the monetary policy coefficients approach zero, consistent with the empirical behavior of bond betas since the financial crisis. A more detailed exploration of this issue would require a separate calibration of the model over the last six years, which is challenging given the limited data currently available.

\section{$5.2 \quad$ Impulse responses}

To gain further insight into the mechanisms of the model that produce the patterns illustrated in Figures 3 and 4, we now report impulse response functions implied by the model in each subperiod. Figure 5 shows the dynamic responses of macroeconomic variables and asset prices to each of the fundamental model shocks, starting from the unconditional mean of the system (an output gap of zero). Each panel shows three lines, each one corresponding to one subperiod calibration. Vertical bars indicate the size of the initial shock reaction. The size of each shock is identical across subperiods, and equal to the sample-size weighted average of the shock standard deviation across subsamples. We consider the responses of the output gap, the inflation gap, the nominal and real interest rates, the dividend-price ratio, and the nominal long-term yield to shocks.

Figure 5 is closely related to the top right panel of Table 8, which shows partial derivatives of the nominal bond beta with respect to each of the shocks. The partial derivative for shock $k$ is proportional to the stock price response interacted with the bond price response to the

shock $\left(A^{e}(k) \times A^{\$, n}(k)\right)$ and hence quantitatively summarizes the partial contribution of shock $k$ to the nominal bond beta. The top panel of Table 8 suggests that Phillips Curve (PC) shocks and inflation target shocks are the main contributors to the nominal bond beta, 
while IS and MP shocks contribute very little.

Figure 5 shows that a typical IS shock raises output temporarily and but it has only a small positive effect on inflation and interest rates in all three subperiods as is evident from the small vertical scale for their impulse responses. Higher expected inflation raises the long-term nominal yield only modestly. The log dividend-price ratio increases, but this increase is short-lived as it is almost exclusively driven by temporarily high dividends; stock prices remain flat since the increase in output and dividends is only temporary. Equation (8) shows that the direct effect of a positive IS shock is to raise marginal utility, but this is counteracted by the endogenous increase in the output gap, and the combined effect on risk premia and stock returns of the shock is close to zero. Thus overall a typical IS shock has a small impact on bond beta.

A Phillips Curve (PC) shock acts as a persistent inflationary and contractionary supply shock, contributing to a positive bond beta for all three subperiod calibrations. The persistent decrease in the output gap raises equity risk premia, lowers stock prices, and raises the dividend-price ratio. Short-term and long-term nominal interest rates increase in response to persistently higher expected inflation. A PC shock moves the log dividend price ratio and bond yields in the same direction and hence contributes to a positive bond beta.

The three subperiod calibrations show differential responses to PC shocks and those differences are related to changes in monetary policy. The positive impact of a PC shock on the long-term nominal yield and the nominal bond beta is strongest in the second subperiod. In this period, the Federal Reserve reacts aggressively and immediately to the increase in inflation, raising the real short rate and driving up nominal bond yields. In addition, because nominal bonds have a positive beta in the second subperiod, their risk premia are especially 
high in times of higher aggregate risk. The recession following a PC shock makes bonds riskier, further increasing nominal bond yields and amplifying the positive bond beta. This is an illustration of the important risk premium channel operative in our model.

On the other hand, more persistent monetary policy in the third subperiod mitigates the positive impact of a PC shock on yields and the nominal bond beta. In this subperiod, the real interest rate initially falls in response to a PC shock and nominal bond yields respond less to a PC shock even in the absence of risk premia. Bonds are safe in the third subperiod and they are especially safe during recessions, further lowering the yield response to a PC shock.

A monetary policy (MP) shock has generally small effects on both the dividend price ratio and the nominal yield and contributes little to bond betas. Because our calibration incorporates a small slope of the IS curve, transitory monetary policy shocks have little effect on the economy. Monetary policy shocks are more persistent in the third subperiod, and they move bonds and stocks in the same direction, pushing the bond beta up. However, the partial derivatives in Table 8 reveal that the magnitude of the effect on the nominal bond beta is extremely small.

Finally, a shock to the central bank's inflation target leads to a delayed but permanent effect on inflation and, except in the second subperiod, generates negative bond betas. During the transition to the new steady state, inflation is below the new target. This boosts output and equity dividends, and lowers the equity premium through reduced risk and risk aversion. The decline in the equity premium pushes stock valuations up beyond the increase in dividends, and the dividend-price ratio declines. The effect of the shock on real and nominal interest rates depends on the monetary policy regime. In the first subperiod, 
the Federal Reserve reacts to the increase in the output gap by raising the nominal short rate. The real rate also increases during the transition period of below-target inflation. The yield on the nominal long-term bond increases, driving bond prices down even while stock prices are rising, contributing to a negative nominal bond beta.

By contrast, in the second subperiod monetary policy does not react strongly to the output gap. The Federal Reserve reacts to inflation below its new target by lowering the real interest rate, which prevents the nominal bond yield from increasing and eliminates the tendency for inflation target volatility to create a negative bond beta. In the long run, as inflation increases, the Federal Reserve allows short-term and long-term nominal interest rates to increase in line with inflation.

In the third subperiod, the impulse response is similar to that in the first subperiod, but for a different reason related to the increase in the monetary policy persistence parameter $\rho^{i}$. While the Federal Reserve still responds to inflation in the third subperiod, it does so much more gradually. The increase in the inflation target, by contrast, feeds directly and immediately into the nominal interest rate, driving up the nominal bond yield and contributing to a negative bond beta. This direct effect of an inflation target shock is reinforced in the third subperiod by the fact that the overall bond beta is negative. During the boom following an inflation target shock, risk aversion declines and the hedge value of Treasury bonds is reduced. This amplifies the negative impact of the shock on nominal bond prices, and makes the bond beta even more negative.

While these impulse responses illustrate the qualitative effects of shocks on bond betas, a full understanding of the changes in betas requires that we take into account changes in the volatilities of these shocks across our three regimes. We turn to this next. 


\subsection{Marginal analysis}

Table 8 analyzes the marginal effect of each parameter on the nominal bond beta, the volatility of nominal bond returns, and the volatility of equity returns across subperiods. We provide derivatives with respect to the MP parameters $\gamma^{x}, \gamma^{\pi}$ and $\rho^{i}$, and also with respect to the log standard deviations of shocks - thus we can interpret the derivatives with respect to the standard deviations of shocks as semi-elasticities. All other parameters are held constant at their 1960.Q1-1979.Q2, 1979.Q3-1996.Q4, or 1997.Q1-2011.Q4 values.

We also decompose the same three asset pricing moments using partial derivatives while holding constant the loadings of bond and stock returns onto the fundamental model shocks $A^{e}$ and $A^{\$, n}$. These partial effects take account of bond and stock responses to each of the fundamental model shocks, similarly to the impulse responses shown in Figure 5, but do not account for the effect of changing volatilities on risk premia. ${ }^{15}$

The top panel in Table 8 shows that the MP inflation coefficient $\gamma^{\pi}$ tends to increase the nominal bond beta, while the MP output gap coefficient $\gamma^{x}$ and MP persistence $\rho^{i}$ tend to decrease the nominal bond beta. Monetary policy persistence has a strongly nonlinear effect on the nominal bond beta, and the magnitude of this effect is particularly large for the 1997.Q1-2011.Q4 calibration. The right columns of the top panel (partial derivatives) show that the nominal bond beta increases in the PC shock volatility and, in the first and particularly in the third subperiod, it decreases in the inflation target shock volatility. IS

\footnotetext{
${ }^{15}$ The nominal bond beta partial semi-elasticity also holds constant the standard deviation of equity returns. Equivalently, this partial semi-elasticity captures the effect of shock volatilities on the covariance of bond and stock returns scaled by the inverse of a constant equity volatility. The nominal bond beta partial semi-elasticities sum to two times the calibrated nominal bond beta for each subperiod. The partial semi-elasticities for the standard deviations of asset returns sum to the calibrated standard deviation of asset returns for each subperiod. The online Appendix presents detailed formulas for partial semi-elasticities.
} 
and MP shock volatilities have very small effects on the nominal bond beta. The signs of the derivatives with respect to log shock volatilities are generally consistent with the signs of the partial derivatives. However, endogenous responses of risk premia and endogenous precautionary saving can drive potentially substantial wedges between total and partial derivatives, as we describe below.

The middle panel of Table 8 shows that the effect of parameters on bond return volatility is especially nonlinear, with some total derivatives switching sign exactly when the nominal bond beta switches sign. But partial derivatives with respect to log shock volatilities, which ignore the endogenous responses of risk premia, are all positive. The partial derivative with respect to $\log \mathrm{PC}$ shock volatility is especially important in the middle subperiod, while the partial derivative with respect to log inflation target volatility is especially important in the most recent subperiod.

The third panel of Table 8 looks at equity return volatility. As with the nominal bond beta and bond return volatility, the volatilities of the PC shock and the inflation target shock are clearly the single most important drivers of equity return volatility in the model. This panel provides two important examples of the importance of endogenous general equilibrium effects in the model. The panel shows that the partial derivative of equity return volatility with respect to $\mathrm{PC}$ shocks is large and positive in all three subperiods, while the total derivative is negative and large in absolute value. An increase in the volatility of PC shocks stimulates precautionary savings and alters the cyclical variation of equilibrium risk premia. These effects are powerful enough to reverse the direct effect of the increased volatility of PC shocks on equity return volatility. A similar mechanism also explains the sign reversal between the partial and total derivatives of equity return volatility with respect to the 
volatility of inflation target shocks.

Table 8 and the impulse response functions in Figure 5 provide a comprehensive picture of the main drivers of bond betas. PC shocks and inflation target shocks pull bond betas in opposite directions. A higher inflation reaction coefficient $\gamma^{\pi}$ implies a more positive yield response to a positive PC shock, amplifying the effect of PC shocks. When the central bank is more concerned about stabilizing output and $\gamma^{x}$ is large, yields increase more strongly in response to an inflation target shock and the effect of inflation target shocks on bond betas is amplified. Finally, a higher monetary policy persistence parameter $\rho^{i}$ decreases the immediate response of the nominal short rate to a PC shock and dampens the effect of PC shocks on nominal bond yields and betas. Risk premia are counter-cyclical when the bond beta is positive and pro-cyclical when the bond beta is negative, providing an important amplification channel.

Table 9 decomposes how each of these forces has contributed to changes in bond and equity risks using the derivatives reported in Table 8. Table 9 weights total derivatives as reported in Table 8 by the corresponding parameter change from one period to the next. We average total derivatives across lagged and led periods. Table 9 also reports the total linearized change in bond and equity risks due to the combined change in monetary policy parameters $\gamma^{x}, \gamma^{\pi}, \rho^{i}, \bar{\sigma}^{M P}$, and $\bar{\sigma}^{*}$ and due to the combined changes in the volatilities of supply and demand shocks $\bar{\sigma}^{I S}$, and $\bar{\sigma}^{M P}$. Comparing the sum of linearized changes in bond and equity risks and the model-implied changes in bond and equity risks gives the change due to model nonlinearity. The linear effects of the individual parameters and the nonlinearity effect sum to the total model change reported at the top of Table 9.

Table 9 shows that the reduction in the central bank's response to output, $\gamma^{x}$, and the 
increase in the central bank's response to inflation, $\gamma^{\pi}$, were important contributors to the increases in the nominal bond beta and the volatility of bond returns that occurred in 1979. On the other hand, changes in the volatility of supply (PC) shocks acted to decrease the nominal bond beta and the volatility of bond returns at the 1979 regime change. Thus monetary policy changes and shock volatility changes offset each other to some degree in 1979.

In 1997, the increase in monetary policy persistence is most important for understanding the decline in the nominal bond beta, but the increase in the central bank's reaction to output also plays a role. The bottom of the table shows that nonlinear interaction effects, for example between the persistence of monetary policy and the volatility of inflation target shocks, are important at both regime changes.

\section{Implications for Inflation-Indexed Bonds}

Inflation-indexed bonds, or Treasury Inflation Protected Securities (TIPS), have been issued in the US since 1997. TIPS have become a meaningful source of funding for the U.S. Treasury and an important investment vehicle for institutional and retail investors (Campbell, Shiller, and Viceira 2009), which makes it interesting to understand monetary policy implications for the second moments of real bond returns. Since TIPS were not available during periods 1 and 2, we can only compare model and empirical real bond return moments for period 3 .

Table 10 shows that in the third subperiod, when inflation-indexed bonds are available, the model-implied inflation-indexed bond beta is negative and quantitatively close to the empirical TIPS beta. We do not use TIPS data in our calibration procedure and TIPS 
moments therefore provide additional verification of the model's out-of-sample performance. The partial derivatives in Table 10 show that PC shocks and inflation target shocks, in conjunction with the monetary policy response to those shocks, are the main drivers of the negative TIPS beta in this subperiod. Figure 5 shows that a PC shock increases inflation and depresses output independently of the monetary policy regime. In the most recent monetary policy regime, the nominal rate is extremely sticky. An increase in inflation therefore leads to a drop in real interest rates and moves TIPS valuations and equity valuations in opposite directions. This mechanism would likely be even stronger for monetary policy at the zero lower bond, when nominal interest rates are constant.

Figure 5 also shows that an inflation target shock boosts output in all three subperiods but does not have an immediate effect on inflation. In the most recent period, monetary policy strongly reacts to output fluctuations, raising the nominal interest rate. Because the shock does not raise inflation immediately, the real rate also increases, moving TIPS valuations lower at a time when stock valuations increase.

Phillips curve shocks and inflation target shocks also explain why our model predicts that, had TIPS been issued in the second subperiod, they would have exhibited a positive beta. The strongly anti-inflationary monetary policy in the second subperiod implies that the central bank reacts to a Phillips curve shock by raising the real interest rate. This, in turn, leads to a fall in the price of TIPS at the same time that output and stock prices are low. Inflation target shocks tend to move the real rate downwards in this subperiod, causing the price of TIPS to rise, while boosting stock prices.

Finally, our model implies that if real bonds had existed during the first subperiod, they would have been safe assets, with a beta even more negative than in the third subperiod. 
Their returns would also have been considerably more volatile than in the two subsequent periods. Table 10 shows that the same factors that push real bond betas lower in the third subperiod also push bond betas lower in the first subperiod. The intuition why real bonds should have been safe during that period hinges on Phillips curve shocks and inflation target shocks. In a regime where the central bank raises the policy rate less than one-for-one with inflation, real bonds do well when the economy experiences an inflationary and contractionary PC shock, implying a negative bond beta. In this same policy regime, an inflation target shock that raises output and stock valuations, while moving the inflation target temporarily above current inflation, leads the central bank to raise real interest rates, driving real bond prices down and again implying a negative real bond beta.

\section{Conclusion}

Given the importance of nominal US Treasury bonds in investment portfolios, and in the design and execution of fiscal and monetary policy, financial economists and macroeconomists need to understand the determinants of Treasury bond risks. This is particularly challenging because the risk characteristics of nominal Treasury bonds are not stable over time.

This paper argues that understanding bond risks requires modeling the influence of monetary policy on the macroeconomy, particularly the relation between output and inflation, and understanding how macroeconomic supply and demand shocks and central bank responses to those shocks affect asset prices. We propose a model that integrates the building blocks of a New Keynesian model into an asset pricing framework in which risk and consequently risk

premia can vary in response to macroeconomic conditions. We calibrate our model to US 
data between 1960 and 2011, a period in which macroeconomic conditions, monetary policy, and bond risks have experienced significant changes. We allow discrete regime changes just before the third quarter of 1979 and the first quarter of 1997.

Our model is sufficiently rich to allow for a detailed exploration of the monetary policy drivers of bond and equity risks. We find that several elements of monetary policy have been especially important drivers of bond risks during the last half century. First, a strong reaction of monetary policy to inflation shocks increases both the beta of nominal bonds and the volatility of nominal bond returns. Large increases in short-term nominal interest rates in response to inflation shocks tend to lower real output and stock prices, while causing bond prices to fall. Our model attributes the large positive beta and high volatility of nominal bonds after 1979 to a change in monetary policy towards a more anti-inflationary stance. Evidence of such a change has been reported by Clarida, Gali, and Gertler (1999) and other papers studying monetary policy regimes, but our model clarifies how this alters the behavior of the bond market.

Second, the response of monetary policy to output is also important. When policy is more responsive to output, interest rates tend to fall in recessions, driving up bond prices. This pattern tends to create a negative beta for nominal bonds. We estimate that monetary policy was less responsive to output between 1979 and 1997 than it was before 1979 and has been since 1997, so this factor helps to explain the high positive bond beta in the 1979-1997 period.

Third, we find that the gradualism of monetary policy, which we identify as an important characteristic of monetary policy starting in 1997, interacts with the other parameters of monetary policy to determine the bond beta. Gradualist monetary policy reduces the 
immediate response of interest rates to both inflation and output, and spreads the response out over time. This helps to explain why inflation target shocks since 1997 have contributed to a negative bond beta, despite the continuing anti-inflationary commitment of the Federal Reserve in this period. These inflation target shocks may be interpreted literally, as the result of shifting central bank preferences, or more broadly as the result of imperfect credibility in monetary policy (Orphanides and Williams 2004).

Our model implies that changes in the volatility of supply shocks, or shocks to the Phillips Curve, can also affect bond risks. Supply shocks, such as oil price shocks, move inflation and output in opposite directions, making bond returns procyclical. They also have a strong effect on the volatility of equity returns. We estimate that the volatility of these shocks decreased after 1979 and remained constant thereafter, which in isolation would act to decrease bond betas. However, the substantial shifts in monetary policy after 1979 dominated changes in the volatility of PC shocks, explaining why we did not see a negative bond beta until 1997.

We find that it is particularly important to take account of changing risk premia. Because macroeconomic volatility is countercyclical in our model, assets with positive betas have risk premia that increase in recessions, driving down their prices and further increasing their betas. Assets with negative betas, on the other hand, become even more desirable hedges during recessions; this increases their prices and makes their betas even more negative. Thus the dynamic responses of risk premia amplify sign changes in betas that originate in changes in monetary policy, and underline the importance of nonlinear effects in understanding the impact of changes in monetary policy and macroeconomic shocks on asset prices.

We show that the model generates empirically plausible betas and volatilities for inflation- 
indexed bonds during the most recent monetary policy regime, which is the only one of our regimes when the US Treasury issued inflation-indexed bonds. This is despite the fact that we did not use inflation-indexed bonds to fit the model.

Our analysis has several limitations that can be addressed in future research. First, since we use a New Keynesian model, the micro-foundations of our model are not as clear and detailed as is standard in the dynamic stochastic general equilibrium literature. We have little to say about the production side of the economy or the labor market. Second, our use of a habit-formation model shuts down the pricing of long-run risks that is the focus of a large literature following Bansal and Yaron (2004). Third, the regime shifts we consider are unanticipated, once-and-for-all events rather than stochastically recurring events whose probabilities are understood by market participants. Finally, we calibrate our model to US historical data but it will be valuable to extend this analysis to comparative international data on monetary policy in relation to bond and stock returns. Countries such as the UK, where inflation-indexed bonds have been issued for several decades, will provide particularly useful evidence on the comparative risks of real and nominal bonds, and their changes over time. 


\section{References}

Abel, Andrew B., 1990, "Asset Prices under Habit Formation and Catching up with the Joneses", American Economic Review Papers and Proceedings 80, 38-42.

An, Sungbae, and Frank Schorfheide, 2007, "Bayesian Analysis of DSGE Models", Econometric Reviews 26, 113-172.

Andreasen, Martin M., 2012, "An Estimated DSGE Model: Explaining Variation in Nominal Term Premia, Real Term Premia, and Inflation Risk Premia", European Economic Review 56, 1656-1674.

Ang, Andrew, Jean Boivin, Sen Dong, and Rudy Loo-Kung, 2011, "Monetary Policy Shifts and the Term Structure", Review of Economic Studies 78, 429-457.

Ang, Andrew and Monika Piazzesi, 2003, "A No-Arbitrage Vector Autoregression of Term Structure Dynamics with Macroeconomic and Latent Variables", Journal of Monetary Economics 50, 745-787.

Ang, Andrew, Sen Dong, and Monika Piazzesi, 2007, "No-Arbitrage Taylor Rules", unpublished paper, Columbia University and University of Chicago.

Ang, Andrew, and Maxim Ulrich, 2012, "Nominal Bonds, Real Bonds, and Equity", unpublished paper, Columbia University.

Backus, David, Mikhail Chernov, and Stanley E. Zin, 2013, "Identifying Taylor Rules in Macro-Finance Models", NBER Working Paper No. 19360.

Baele, Lieven, Geert Bekaert, and Koen Inghelbrecht, 2010, "The Determinants of Stock and Bond Return Comovements", Review of Financial Studies 23, 2374-2428.

Ball, Laurence and Stephen Cecchetti, 1990, "Inflation and Uncertainty at Long and Short Horizons", Brookings Papers on Economic Activity 1, 215-245.

Bansal, Ravi and Ivan Shaliastovich, 2013, "A Long-Run Risks Explanation of Predictability Puzzles in Bond and Currency Markets", Review of Financial Studies 26, 1-33.

Bansal, Ravi, and Amir Yaron, 2004, "Risks for the Long Run: A Potential Resolution of Asset Pricing Puzzles," Journal of Finance 59, 1481-1509.

Barsky, Robert B., 1989, "Why Don't the Prices of Stocks and Bonds Move Together?", American Economic Review 79, 1132-1145. 
Bekaert, Geert, Seonghoon Cho, and Antonio Moreno, 2010, "New Keynesian Macroeconomics and the Term Structure", Journal of Money, Credit, and Banking 42, 33-62.

Bekaert, Geert, Eric Engstrom, and Steve Grenadier, 2010, "Stock and Bond Returns with Moody Investors", Journal of Empirical Finance 17, 867-894.

Bekaert, Geert, Eric Engstrom, and Yuhang Xing, 2009, "Risk, Uncertainty, and Asset Prices", Journal of Financial Economics 91, 59-82.

Bernanke, Ben S., 2004, "Gradualism," remarks by Governor Ben S. Bernanke at an economics luncheon co-sponsored by the Federal Reserve Bank of San Francisco (Seattle Branch) and the University of Washington, Seattle, Washington May 20, 2004. Available online at www.federalreserve.gov/boarddocs/speeches/2004/200405202/.

Bikbov, Ruslan and Mikhail Chernov, 2013, "Monetary Policy Regimes and the Term Structure of Interest Rates", Journal of Econometrics 174, 27-43.

Van Binsbergen, Jules H., Jesús Fernández-Villaverde, Ralph Koijen, and Juan RubioRamírez, 2012, "The Term Structure of Interest Rates in a DSGE Model with Recursive Preferences", Journal of Monetary Economics 59, 634-648.

Burkhardt, Dominic and Henrik Hasseltoft, 2012, "Understanding Asset Correlations", unpublished paper, University of Zurich and Swiss Finance Institute.

Boivin, Jean, and Marc P. Giannoni, 2006, "Has Monetary Policy Become More Effective?", Review of Economics and Statistics 88, 445-462.

Buraschi, Andrea and Alexei Jiltsov, 2005, "Inflation Risk Premia and the Expectations Hypothesis", Journal of Financial Economics 75, 429-490.

Buraschi, Andrea and Alexei Jiltsov, 2007, "Habit Formation and Macroeconomic Models of the Term Structure of Interest Rates", Journal of Finance 62, 3009-3063.

Calvo, Guillermo, 1983, "Staggered Prices in a Utility Maximizing Framework", Journal of Monetary Economics 12, 383-98.

Campbell, John Y., 1986, "Bond and Stock Returns in a Simple Exchange Model", Quarterly Journal of Economics 101, 785-803.

Campbell, John Y., 1991, "A Variance Decomposition for Stock Returns", Economic Journal 101:157-179.

Campbell, John Y., 2003, "Consumption-Based Asset Pricing", Chapter 13 in George Constantinides, Milton Harris, and Rene Stulz eds. Handbook of the Economics of Finance Vol. IB, North-Holland, Amsterdam, 803-887. 
Campbell, John Y. and John Ammer, 1993, "What Moves the Stock and Bond Markets? A Variance Decomposition for Long-Term Asset Returns", Journal of Finance 48, 3-37.

Campbell, John Y. and John H. Cochrane, 1999, "By Force of Habit: A Consumption-Based Explanation of Aggregate Stock Market Behavior", Journal of Political Economy 107, 205-251.

Campbell, John Y., Carolin Pflueger, and Luis Viceira, 2013, "Appendix to Monetary Policy Drivers of Bond and Equity Risks", online at http://scholar.harvard.edu/campbell/publications.

Campbell, John Y., Robert J. Shiller, and Luis M. Viceira, 2009, "Understanding InflationIndexed Bond Markets", Brookings Papers on Economic Activity 79-120, Spring 2009.

Campbell, John Y., Adi Sunderam, and Luis M. Viceira, 2013, "Inflation Bets or Deflation Hedges? The Changing Risks of Nominal Bonds", unpublished paper, Harvard University.

Canova, Fabio, and Luca Sala, 2009, "Back to Square One: Identification Issues in DSGE Models" Journal of Monetary Economics, 56, 431-449.

Chen, Nai-fu, 1991, "Financial Investment Opportunities and the Macroeconomy", Journal of Finance 46, 529-554.

Chib, Siddhartha, Kyu Ho Kang, and Srikanth Ramamurthy, 2010, "Term Structure of Interest Rates in a DSGE Model with Regime Changes", unpublished paper, Washington University in St. Louis.

Cho, Seonghoon, and Antonio Moreno, 2011, "The Forward Method as a Solution Refinement in Rational Expectations Models", Journal of Economic Dynamics and Control $35,257-272$.

Christiano, Lawrence J., Martin Eichenbaum, and Charles L. Evans, 1999, "Monetary Policy Shocks: What Have We Learned and to What End?", in John B. Taylor and Michael Woodford (eds.) Handbook of Macroeconomics 1999, 65-148, Elsevier.

Christiano, Lawrence J., Martin Eichenbaum, and Charles L. Evans, 2005, "Nominal Rigidities and the Dynamic Effects of a Shock to Monetary Policy", Journal of Political Economy 113, 1-45.

Christiansen, Charlotte and Angelo Ranaldo, 2007, "Realized Bond-Stock Correlation: Macroeconomic Announcement Effects", Journal of Futures Markets 27, 439-469.

Clarida, Richard, Jordi Gali, and Mark Gertler, 1999, "The Science of Monetary Policy: A New Keynesian Perspective", Journal of Economic Literature 37, 1661-1707. 
Cochrane, John H., 2007, "Financial Markets and the Real Economy", in Rajnish Mehra ed. Handbook of the Equity Premium, Elsevier, 237-325.

Cochrane, John H., 2011, "Determinacy and Identification with Taylor Rules," Journal of Political Economy 119, 565-615.

Cochrane, John H. and Monika Piazzesi, 2005, "Bond Risk Premia", American Economic Review 95, 138-160.

Coibion, Olivier and Yuriy Gorodnichenko, 2012, "Why Are Target Interest Rate Changes So Persistent?", American Economic Journal: Macroeconomics 4, 126-162.

d'Addona, Stefano and Axel H. Kind, 2006, "International Stock-Bond Correlations in a Simple Affine Asset Pricing Model", Journal of Banking and Finance 30, 2747-2765.

Dai, Qiang and Kenneth Singleton, 2000, "Specification Analysis of Affine Term Structure Models", Journal of Finance 55, 1943-1978.

Dai, Qiang and Kenneth Singleton, 2002, "Expectations Puzzles, Time-Varying Risk Premia, and Affine Models of the Term Structure", Journal of Financial Economics 63, 415-442.

David, Alexander and Pietro Veronesi, 2013, "What Ties Return Volatilities to Fundamentals and Price Valuations?", Journal of Political Economy 121, 682-746.

Dew-Becker, Ian, 2013, "A Model of Time-Varying Risk Premia with Habits and Production", unpublished paper, Duke University.

Dew-Becker, Ian, 2014, "Bond Pricing with a Time-Varying Price of Risk in an Estimated Medium-Scale New Keynesian Model", forthcoming Journal of Money, Credit, and Banking.

Duffee, Greg, 2002, "Term Premia and Interest Rate Forecasts in Affine Models", Journal of Finance 57, 405-443.

Duffie, Darrell and Rui Kan, 1996, "A Yield-Factor Model of Interest Rates", Mathematical Finance 6, 379-406.

Eraker, Bjørn, 2008, “Affine General Equilibrium Models", Management Science 54, 20682080.

Evans, George, 1985, "Expectational Stability and the Multiple Equilibria Problem in Linear Rational Expectations", The Quarterly Journal of Economics 100, 1217-1233. 
Evans, George, 1986, "Selection Criteria for Models with Non-Uniqueness", Journal of Monetary Economics 18, 147-157.

Fama, Eugene F., 1990, "Stock Returns, Expected Returns, and Real Activity", Journal of Finance 45, 1089-1108.

Fama, Eugene F. and Kenneth R. French, 1989, "Business Conditions and Expected Returns on Stocks and Bonds", Journal of Financial Economics 25, 23-50.

Fuhrer, Jeffrey C., 1997, "The (Un)Importance of Forward-Looking Behavior in Price Specifications", Journal of Money, Credit, and Banking 29, 338-350.

Fuhrer, Jeffrey C., 2000, "Habit Formation in Consumption and Its Implications for MonetaryPolicy Models", American Economic Review 90, 367-390.

Gali, Jordi, and Mark Gertler, 1999, "Inflation Dynamics: A Structural Econometric Analysis", Journal of Monetary Economics 44, 195-222.

Greenspan, Alan, 1996, "The Challenge of Central Banking in a Democratic Society", remarks by Chairman Alan Greenspan at the Annual Dinner and Francis Boyer Lecture of The American Enterprise Institute for Public Policy Research, Washington, D.C., December 5. Available online at http://www.federalreserve.gov/newsevents/speech/1996speech.htm.

Gallmeyer, Michael, Burton Hollifield, Francisco Palomino, and Stanley Zin, 2008, "Term Premium Dynamics and the Taylor Rule", unpublished paper, Texas A\&M University, Carnegie Mellon University, and University of Michigan.

Guidolin, Massimo, and Allan Timmermann, 2007, "Asset Allocation under Multivariate Regime Switching", Journal of Economic Dynamics and Control 31, 3503-3544.

Hall, Robert E., 1988, "Intertemporal Substitution in Consumption", Journal of Political Economy 96, 221-273.

Hamilton, James, 2009, "Causes and Consequences of the Oil Shock of 2007-08", Brookings Papers on Economic Activity 215-261, Spring 2009.

Hamilton, James, Seth Pruitt, and Scott Borger, 2011, "Estimating the Market-Perceived Monetary Policy Rule", American Economic Journal: Macroeconomics 3, 1-28.

Hasseltoft, Henrik, 2008, "The 'Fed-Model' and the Changing Correlation of Stock and Bond Returns: An Equilibrium Approach", unpublished paper, Stockholm School of Economics.

Koijen, Ralph, Hanno Lustig, and Stijn Van Nieuwerburgh, 2010, "The Cross-Section and Time-Series of Stock and Bond Returns", NBER working paper No. 15688. 
Kung, Howard, 2013, "Macroeconomic Linkages Between Monetary Policy and the Term Structure of Interest Rates", Journal of Financial Economics, forthcoming.

Lamont, Owen, 1998, "Earnings and Expected Returns", Journal of Finance 53, 1563-1587.

Lettau, Martin and Sydney Ludvigson, 2001, "Consumption, Aggregate Wealth, and Expected Stock Returns", Journal of Finance 56, 815-849.

Lettau, Martin and Jessica Wachter, 2011, "The Term Structures of Equity and Interest Rates", Journal of Financial Economics 101, 90-113.

Li, Erica X.N. and Francisco Palomino, 2013, "Nominal Rigidities, Asset Returns, and Monetary Policy", unpublished paper, Cheung Kong Graduate School of Business and University of Michigan.

Mankiw, N. Gregory, and Ricardo Reis, 2002, "Sticky Information Versus Sticky Prices: A Proposal to Replace the New Keynesian Phillips Curve", Quarterly Journal of Economics 177, 1295-1328.

McCallum, Bennett T., 2003, "Multiple-Solution Indeterminacies in Monetary Policy Analysis", Journal of Monetary Economics 50, 1153-1175.

McCallum, Bennett T., 2004, "On the Relationship Between Determinate and MSV Solutions in Linear RE Models", Economics Letters 84, 55-60.

Orphanides, Athanasios (2003). "Monetary Policy Evaluation with Noisy Information," Journal of Monetary Economics, 50 (April), pp. 605-31.

Orphanides, Athanasios and John Williams, 2004, "Imperfect Knowledge, Inflation Expectations, and Monetary Policy", Chapter 5 in Ben S. Bernanke and Michael Woodford eds. The Inflation-Targeting Debate, University of Chicago Press.

Palomino, Francisco, 2012, "Bond Risk Premiums and Optimal Monetary Policy", Review of Economic Dynamics 15, 19-40.

Piazzesi, Monika and Martin Schneider, 2006, "Equilibrium Yield Curves", in D. Acemoglu, K. Rogoff, and M. Woodford (eds.) NBER Macroeconomics Annual 2006, 317-363, MIT Press, Cambridge, MA.

Rigobon, Roberto and Brian Sack, 2003, "Measuring the Reaction of Monetary Policy to the Stock Market", Quarterly Journal of Economics 639-669. 
Rotemberg, Julio and Michael Woodford, 1997, "An Optimization-Based Econometric Framework for the Evaluation of Monetary Policy", in Ben S. Bernanke and Julio Rotemberg (eds.) NBER Macroeconomics Annual 1997, 297-361, MIT Press, Cambridge, MA.

Rudebusch, Glenn D., 2002, "Term Structure Evidence on Interest Rate Smoothing and Monetary Policy Inertia", Journal of Monetary Economics 49, 1161-1187.

Rudebusch, Glenn D. and Eric T. Swanson, 2012, "The Bond Premium in a DSGE Model with Long-Run Real and Nominal Risks", American Economic Journal: Macroeconomics 4, 105-143.

Rudebusch, Glenn D. and Tao Wu, 2007, "Accounting for a Shift in Term Structure Behavior with No-Arbitrage and Macro-Finance Models", Journal of Money, Credit, and Banking 39, 395-422.

Rudebusch, Glenn D. and Tao Wu, 2008, "A Macro-Finance Model of the Term Structure, Monetary Policy, and the Economy", Economic Journal 118, 906-926.

Shiller, Robert J. and Andrea Beltratti, 1992,"Stock Prices and Bond Yields: Can Their Comovements Be Explained in Terms of Present Value Models?", Journal of Monetary Economics 30, 25-46.

Smets, Frank, and Rafael Wouters, 2007, "Shocks and Frictions in US Business Cycles: A Bayesian DSGE Approach", American Economic Review 97, 586-606.

Smith, Josephine M. and John B. Taylor, 2009, "The Term Structure of Policy Rules", Journal of Monetary Economics 56, 907-917.

Stein, Jeremy C., 2013, "Gradualism in Monetary Policy: A Time-Consistency Problem?", unpublished notes.

Stock, James H. and Mark Watson, 2007, "Why Has US Inflation Become Harder to Forecast?", Journal of Money Credit and Banking 39, 3-33.

Taylor, John B., 1980, "Aggregate Dynamics and Staggered Contracts", Journal of Political Economy 88, 1-23.

Taylor, John B., 1993, "Discretion versus Policy Rules in Practice", Carnegie-Rochester Conference Series on Public Policy 39, 195-214.

Uhlig, Harald, 1999, "A Toolkit for Analyzing Nonlinear Dynamic Stochastic Models Easily", in Ramon Marimon and Andrew Scott (eds.) Computational Methods for the Study of Dynamic Economies, 30-61, Oxford University Press. 
Viceira, Luis M., 2012, "Bond Risk, Bond Return Volatility, and the Term Structure of Interest Rates", International Journal of Forecasting 28, 97-117.

Wachter, Jessica A., 2006, "A Consumption-Based Model of the Term Structure of Interest Rates", Journal of Financial Economics 79, 365-399.

Woodford, Michael, 2001, "The Taylor Rule and Optimal Monetary Policy", American Economic Review Papers and Proceedings 91, 232-237.

Woodford, Michael, 2003, Interest and Prices: Foundations of a Theory of Monetary Policy, Princeton University Press, Princeton, NJ.

Yogo, Motohiro, 2004, "Estimating the Elasticity of Intertemporal Substitution When Instruments Are Weak", Review of Economics and Statistics 86, 797-810. 


\section{Tables and Figures}

Table 1: Summary Statistics

\begin{tabular}{lrrrr} 
1960.Q1-2011.Q4 & Output Gap & Inflation & Fed Funds & Nom. Bond Yield \\
\hline Mean & -0.77 & 3.50 & 5.78 & 6.24 \\
Std. & 2.91 & 2.38 & 3.77 & 2.75 \\
AR(1) Coefficient & 0.96 & 0.88 & 0.89 & 0.98 \\
& $(0.02)$ & $(0.03)$ & $(0.03)$ & $(0.02)$ \\
AR(4) Coefficient & 0.73 & 0.79 & 0.81 & 0.91 \\
& $(0.05)$ & $(0.04)$ & $(0.04)$ & $(0.03)$ \\
& & & & \\
1960.Q1-1979.Q2 & Output Gap & Inflation & Fed Funds & Nom. Bond Yield \\
\hline Mean & 0.64 & 4.38 & 5.27 & 5.80 \\
Std. & 2.79 & 2.72 & 2.45 & 1.63 \\
AR(1) Coefficient & 0.93 & 0.88 & 0.86 & 0.96 \\
& $(0.04)$ & $(0.06)$ & $(0.06)$ & $(0.35)$ \\
AR(4) Coefficient & 0.61 & 0.78 & 0.60 & 0.92 \\
& $(0.09)$ & $(0.07)$ & $(0.10)$ & $(0.06)$ \\
1979.Q3-1996.Q4 & & & & \\
\hline Mean & -1.92 & 3.76 & 8.67 & 8.73 \\
Std. & 2.14 & 2.24 & 4.04 & 2.55 \\
AR(1) Coefficient & 0.93 & 0.87 & 0.78 & 0.94 \\
& $(0.04)$ & $(0.05)$ & $(0.08)$ & $(0.04)$ \\
AR(4) Coefficient & 0.50 & 0.78 & 0.74 & 0.77 \\
& $(0.10)$ & $(0.06)$ & $(0.08)$ & $(0.08)$ \\
1997.Q1-2011.Q4 & Output Gap & Inflation & Fed Funds & Nom. Bond Yield \\
\hline Mean & -1.27 & 2.06 & 3.08 & 3.90 \\
Std. & 3.13 & 1.01 & 2.32 & 1.51 \\
AR(1) Coefficient & 1.00 & 0.51 & 0.95 & 0.94 \\
& $(0.03)$ & $(0.12)$ & $(0.04)$ & $(0.05)$ \\
AR(4) Coefficient & 0.89 & 0.28 & 0.78 & 0.80 \\
& $(0.09)$ & $(0.13)$ & $(0.09)$ & $(0.08)$ \\
\hline
\end{tabular}

Full sample and sub period summary statistics. US quarterly log output gap (\%), GDP deflator inflation (\%, Annualized), Fed Funds rate (\%, Annualized), and 5 year nominal yield (\%, Annualized). Yields and inflation continuously compounded. Standard errors in parentheses. 


\section{Table 2: Predicting Stock Returns with Output Gap}

\begin{tabular}{lcccc} 
Log Exc. Stock Ret. $x r_{t+1}^{e}$ & 60.Q1-11.Q4 & 60.Q1-79.Q2 & 79.Q2-96.Q4 & 97.Q1-11.Q4 \\
\hline Output Gap $x_{t}$ & $-0.49^{*}$ & $-0.61^{*}$ & -0.32 & -0.47 \\
& $(0.20)$ & $(0.30)$ & $(0.48)$ & $(0.40)$ \\
Constant & 0.59 & 0.81 & 1.12 & 0.18 \\
& $(0.61)$ & $(0.95)$ & $(1.14)$ & $(1.36)$ \\
\hline $\mathrm{R}^{2}$ & 0.03 & 0.04 & 0.01 & 0.02 \\
\hline
\end{tabular}

Quarterly realized log excess stock returns (\%, Quarterly) from quarter $t$ to quarter $t+1$ onto the output gap (\%) in quarter $t$. Newey-West standard errors with 2 lags in parentheses. * and ${ }^{* *}$ denote significance at the $1 \%$ and $5 \%$ levels.

Table 3: Predicting Stock Returns with Dividend Price Ratio

\begin{tabular}{lccccc} 
Log Exc. Stock Ret. $x r_{t \rightarrow t+k}^{e}$ & $\mathrm{k}=4$ & $\mathrm{k}=8$ & $\mathrm{k}=12$ & $\mathrm{k}=16$ & $\mathrm{k}=20$ \\
\hline Log Dividend Price Ratio $d_{t}-p_{t}$ & 0.08 & 0.15 & $0.19^{*}$ & $0.21^{* *}$ & $0.25^{* *}$ \\
& $(0.05)$ & $(0.09)$ & $(0.09)$ & $(0.08)$ & $(0.06)$ \\
Constant & 0.34 & $0.62^{*}$ & $0.79^{*}$ & $0.91^{* *}$ & $1.10^{* *}$ \\
& $(0.18)$ & $(0.29)$ & $(0.31)$ & $(0.27)$ & $(0.23)$ \\
\hline $\mathrm{R}^{2}$ & 0.04 & 0.07 & 0.09 & 0.10 & 0.12 \\
Sample & \multicolumn{5}{c}{ 1960.Q1-2011.Q1 } \\
\hline
\end{tabular}

\begin{tabular}{lccccc}
$x r_{t \rightarrow t+k}^{e}$ & $\mathrm{k}=4$ & $\mathrm{k}=8$ & $\mathrm{k}=12$ & $\mathrm{k}=16$ & $\mathrm{k}=20$ \\
\hline Log Dividend Price Ratio $d_{t}-p_{t}$ & $0.11^{*}$ & $0.21^{* *}$ & $0.28^{* *}$ & $0.34^{* *}$ & $0.43^{* *}$ \\
& $(0.04)$ & $(0.07)$ & $(0.08)$ & $(0.09)$ & $(0.10)$ \\
Constant & $0.44^{* *}$ & $0.82^{* *}$ & $1.13^{* *}$ & $1.40^{* *}$ & $1.76^{* *}$ \\
& $(0.15)$ & $(0.24)$ & $(0.27)$ & $(0.29)$ & $(0.33)$ \\
\hline $\mathrm{R}^{2}$ & 0.08 & 0.15 & 0.22 & 0.27 & 0.33 \\
Sample & \multicolumn{5}{c}{$1947 . \mathrm{Q} 1-2011 . \mathrm{Q} 4$} \\
\hline
\end{tabular}

$k$ quarter log excess stock returns onto lagged log dividend price ratio, both in natural units. Newey-West standard errors with $k+4$ lags in parentheses. ${ }^{*}$ and ${ }^{* *}$ denote significance at the $1 \%$ and $5 \%$ levels. 


\section{Table 4: Estimating the Monetary Policy Function}

\begin{tabular}{lcccc} 
Fed Funds $i_{t}$ & 60.Q1-11.Q4 & 60.Q1-79.Q2 & 79.Q3-96.Q4 & 97.Q1-11.Q4 \\
\hline Output Gap $x_{t}$ & 0.06 & $0.18^{* *}$ & -0.04 & 0.05 \\
& $(0.04)$ & $(0.06)$ & $(0.13)$ & $(0.04)$ \\
Inflation $\pi_{t}$ & 0.21 & $0.30^{* *}$ & $0.83^{* *}$ & $0.21^{* *}$ \\
& $(0.11)$ & $(0.07)$ & $(0.21)$ & $(0.07)$ \\
Lagged Fed Funds $i_{t-1}$ & $0.81^{* *}$ & $0.56^{* *}$ & $0.43^{*}$ & $0.89^{* *}$ \\
& $(0.05)$ & $(0.10)$ & $(0.17)$ & $(0.06)$ \\
Constant & 0.42 & $0.91^{*}$ & 1.75 & -0.12 \\
& $(0.26)$ & $(0.38)$ & $(0.92)$ & $(0.29)$ \\
\hline$R^{2}$ & 0.79 & 0.75 & 0.69 & 0.91 \\
Implied $\hat{\gamma}^{x}$ & 0.32 & $0.42^{* *}$ & -0.07 & 0.44 \\
& $(0.21)$ & $(0.13)$ & $(0.22)$ & $(0.21)$ \\
Implied $\hat{\gamma}^{\pi}$ & $1.08^{* *}$ & $0.69^{* *}$ & $1.44^{* *}$ & $1.92^{*}$ \\
& $(0.43)$ & $(0.16)$ & $(0.19)$ & $(1.26)$ \\
Implied $\hat{\rho}^{i}$ & $0.81^{* *}$ & $0.56^{* *}$ & $0.43^{* *}$ & $0.89^{* *}$ \\
& $(0.05)$ & $(0.10)$ & $(0.17)$ & $(0.06)$ \\
\hline
\end{tabular}

We estimate $i_{t}=c^{0}+c^{x} x_{t}+c^{\pi} \pi_{t}+c^{i} i_{t-1}+\epsilon_{t}$. All variables are described in Table 1 . Since the inflation target is not directly observable it is omitted. Implied parameters are calculated according to $\hat{\rho}^{i}=\hat{c}^{i}, \hat{\gamma}^{x}=\hat{c}^{x} /\left(1-\hat{c}^{i}\right)$, and $\hat{\gamma}^{\pi}=\hat{c}^{\pi} /\left(1-\hat{c}^{i}\right)$. Newey-West standard errors with 6 lags in parentheses. Standard errors for $\hat{\gamma}^{x}$ and $\hat{\gamma}^{\pi}$ are calculated by the delta method. ${ }^{*}$ and ${ }^{* *}$ denote significance at the $5 \%$ and $1 \%$ levels. Significance levels for implied parameters are based on an ordinary least squares likelihood ratio test. 
Table 5: Parameter Choices

\section{Panel A: Calibration Parameters}

Time-Invariant Parameters

$\begin{array}{lcccc}\text { Log-Linearization Constant } & \rho & & 0.99 & \\ \text { Leverage Parameter } & \delta & & 2.43 & \\ \text { Preference Parameter } & \alpha & & 19.06 & \\ \text { Heteroskedasticity Parameter } & b & & 0.73 & \\ \text { SDF Lag Parameter } & \theta & & 0.50 & \\ \text { Backward-Looking Com. PC } & \rho^{\pi} & & 0.96 & \\ \text { Slope PC } & \lambda & & 0.04 & \\ & & & & \\ \text { Monetary Policy Rule } & \text { 60.Q1-79.Q2 } & \text { 79.Q3-96.Q4 } & 97 . Q 1-11 . Q 4 & \\ \text { MP Coefficient Output } & \gamma^{x} & 0.42 & -0.07 & 0.44 \\ \text { MP Coefficient Infl. } & \gamma^{\pi} & 0.69 & 1.44 & 1.92 \\ \text { Backward-Looking Comp. MP } & \rho^{i} & 0.56 & 0.43 & 0.89\end{array}$

Calibrated Std. Shocks

\begin{tabular}{lcccc}
\hline Std. IS & $\sigma^{I S}$ & 0.14 & 0.12 & 0.16 \\
Std. PC shock & $\sigma^{P C}$ & 1.07 & 0.45 & 0.50 \\
Std. MP shock & $\sigma^{M P}$ & 1.35 & 1.85 & 0.32 \\
Std. infl. target shock & $\sigma^{*}$ & 0.32 & 0.68 & 0.75 \\
\hline
\end{tabular}

\section{Panel B: Implied Parameters}

Time-Varying Parameters

\begin{tabular}{lcccc} 
Slope IS & $\psi$ & 0.04 & 0.04 & 0.04 \\
SDF Lag with Varying Risk Premia & $\theta^{*}$ & 0.47 & 0.48 & 0.48 \\
Backward-Looking Comp. IS & $\rho^{x-}$ & 0.34 & 0.34 & 0.34 \\
Forward-Looking Com. IS & $\rho^{x+}$ & 0.68 & 0.68 & 0.68 \\
Std. $s_{t}+c_{t}$ & $\sigma$ & 0.68 & 0.58 & 0.60 \\
\hline
\end{tabular}


Table 6: Model and Empirical Moments

\begin{tabular}{|c|c|c|c|c|c|c|}
\hline Std. VAR(1) Residuals & $\begin{array}{c}\text { 60.Q1-79.Q2 } \\
\text { Empirical }\end{array}$ & $\begin{array}{c}\text { 60.Q1-79.Q2 } \\
\text { Model }\end{array}$ & $\begin{array}{c}\text { 79.Q3-96.Q4 } \\
\text { Empirical }\end{array}$ & $\begin{array}{c}\text { 79.Q3-96.Q4 } \\
\text { Model }\end{array}$ & $\begin{array}{c}\text { 97.Q1-11.Q4 } \\
\text { Empirical }\end{array}$ & $\begin{array}{l}\text { 97.Q1-11.Q4 } \\
\text { Model }\end{array}$ \\
\hline Output Gap & 0.92 & 0.71 & 0.75 & 0.60 & 0.65 & 0.64 \\
\hline Inflation & 1.12 & 1.08 & 0.89 & 0.46 & 0.80 & 0.50 \\
\hline Fed Funds Rate & 1.22 & 1.39 & 2.07 & 1.90 & 0.66 & 0.70 \\
\hline Log Nominal Yield & 0.48 & 0.38 & 0.85 & 0.59 & 0.55 & 0.59 \\
\hline \multicolumn{7}{|l|}{ Std. Asset Returns } \\
\hline Std. Eq. Ret. & 17.62 & 21.17 & 15.34 & 18.93 & 20.08 & 19.17 \\
\hline Std. Nom. Bond Ret. & 4.85 & 3.62 & 9.11 & 5.66 & 5.55 & 5.49 \\
\hline Nominal Bond Beta & $0.06^{*}$ & 0.07 & $0.20^{*}$ & 0.22 & $-0.17^{* *}$ & -0.18 \\
\hline \multicolumn{7}{|c|}{ Taylor Rule: Fed Funds onto Output, Infl. and Lag. Fed Funds } \\
\hline Output & $0.18^{* *}$ & 0.28 & -0.04 & -0.21 & 0.05 & 0.01 \\
\hline Inflation & $0.30^{* *}$ & 0.42 & $0.83^{* *}$ & 0.60 & $0.21^{* *}$ & 0.15 \\
\hline Lagged Fed Funds & $0.56^{* *}$ & 0.56 & $0.43^{* *}$ & 0.40 & $0.89 * *$ & 0.83 \\
\hline
\end{tabular}

This table reports model second moments, conditional on the output gap $x_{t}$ being at its unconditional mean of zero. By the law of total variance, unconditional second moments are equal to conditional second moments at $x_{t}=0$. For details of the derivation, see the Appendix. $*$ and ${ }^{* *}$ denote significance at the $5 \%$ and $1 \%$ levels. We use Newey-West standard erros with 2 lags for the nominal bond beta and Newey-West standard errors with 6 lags for the empirical Taylor rule estimation in the bottom panel. 
Table 7: Additional Empirical and Model Moments

\begin{tabular}{lcc} 
& Empirical & Model \\
\hline AR(1) Coefficient Output Gap & 0.96 & 0.97 \\
AR(4) Coefficient Output Gap & 0.73 & 0.81 \\
Correlation(x, p-d) & 0.18 & 0.96 \\
Std(d-p) & 0.40 & 0.21 \\
AR(4) Coefficient d-p & 0.92 & 0.71 \\
Slope 1 year exc. Stock ret. wrt d-p & 0.08 & 0.31 \\
Slope 5 year exc. Stock ret. wrt d-p & 0.25 & 1.10 \\
Slope quarterly stock ret. wrt x & -0.49 & -0.50 \\
Std(real rate) (Percent, Ann.) & & 2.36 \\
Regression s+c onto x & & 0.51 \\
\hline
\end{tabular}

Additional model and empirical moments are not explicitly fitted by the calibration procedure. Model moments show averages across three sub sample calibrations weighted by sub sample length. Wold's theorem for vector processes implies that the unconditional second moments of the state variables are identical for conditionally homoskedastic and heteroskedastic VAR(1) processes with identical unconditional variance-covariance matrix of innovations. We therefore use a $\operatorname{VAR}(1)$ with matrix of slope coefficients $P$ and conditionally homoskedastic, iid vector of innovations $\epsilon_{t} \sim N\left(0, Q \Sigma_{u} Q^{\prime}\right)$ to simulate all model moments. For details of the derivation, see the Appendix. 
Table 8: Marginal Effects of Parameters

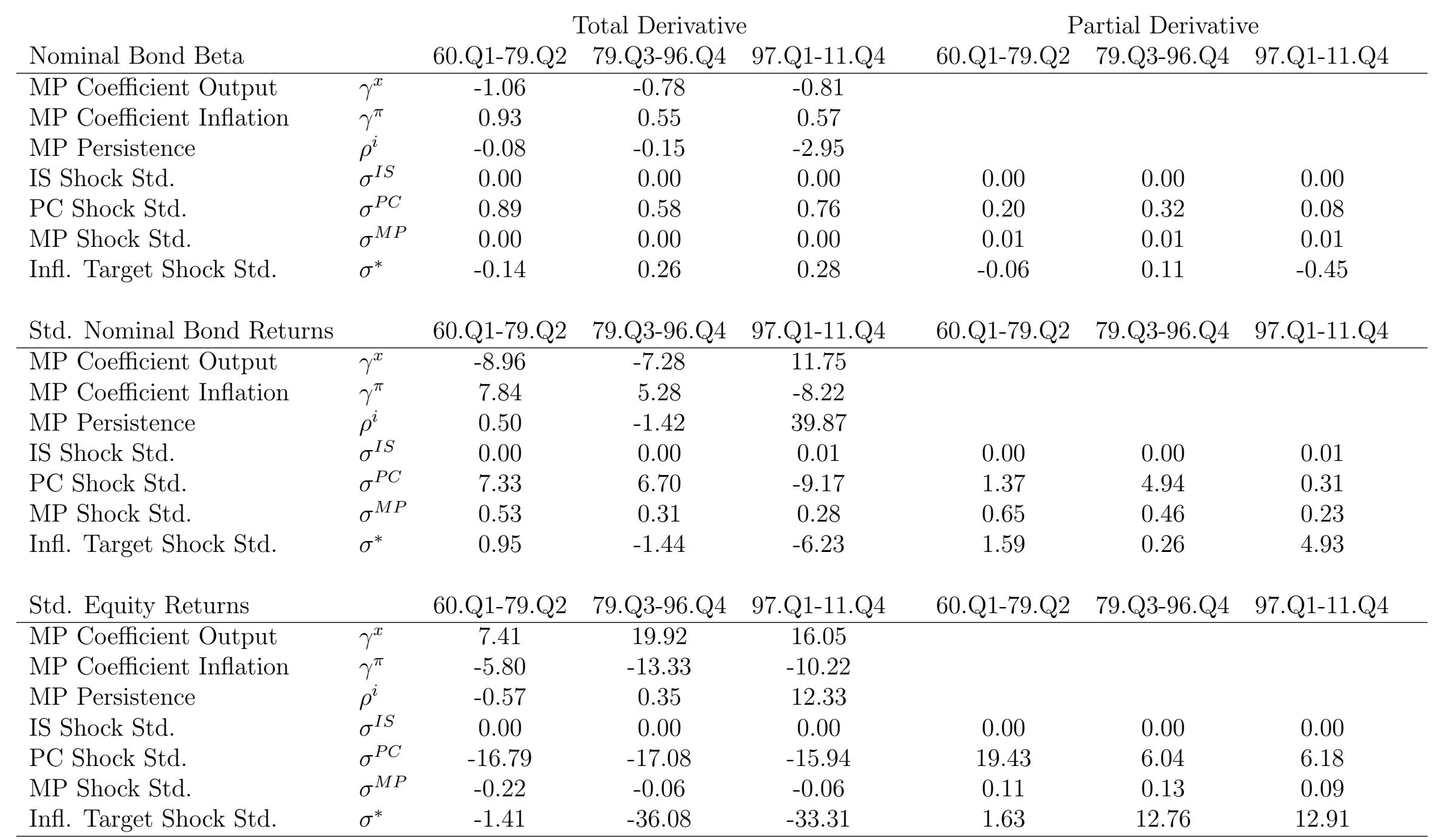

Derivatives with respect to monetary policy rule parameters and log standard deviations of shocks (semi-elasticities). Partial derivatives hold constant the loadings of bond and stock returns. Nominal bond beta partial derivatives also hold equity volatility constant. 
Table 9: Decomposing Changes in Bond and Equity Risks

\begin{tabular}{|c|c|c|c|c|c|c|}
\hline \multirow[b]{2}{*}{ Change Date } & \multicolumn{2}{|c|}{ Nominal Bond Beta } & \multicolumn{2}{|c|}{ Std. Nom. Bond Returns } & \multicolumn{2}{|c|}{ Std. Equity Returns } \\
\hline & 79.Q3 & 97.Q1 & 79.Q3 & 97.Q1 & 79.Q3 & 97.Q1 \\
\hline Empirical Change & 0.13 & -0.36 & 4.26 & -3.56 & -2.28 & 4.74 \\
\hline Model Change & 0.14 & -0.40 & 2.04 & -0.17 & -2.24 & 0.24 \\
\hline
\end{tabular}

Total Derivative x Parameter Change

\begin{tabular}{|c|c|c|c|c|c|c|c|}
\hline Empirical Change & & 0.13 & -0.36 & 4.26 & -3.56 & -2.28 & 4.74 \\
\hline Model Change & & 0.14 & -0.40 & 2.04 & -0.17 & -2.24 & 0.24 \\
\hline \multicolumn{8}{|c|}{ Total Derivative x Parameter Change } \\
\hline MP Coefficient Output & $\gamma^{x}$ & 0.45 & -0.41 & 3.98 & 0.78 & -6.50 & 9.35 \\
\hline MP Coefficient Inflation & $\gamma^{\pi}$ & 0.56 & 0.27 & 5.00 & -0.45 & -7.05 & -5.63 \\
\hline MP Persistence & $\rho^{i}$ & 0.02 & -0.67 & 0.06 & 8.21 & 0.02 & 2.74 \\
\hline MP Shock Std. & $\sigma^{M P}$ & 0.00 & -0.01 & 0.13 & -0.52 & -0.05 & 0.11 \\
\hline Infl. Target Shock Std. & $\sigma^{*}$ & 0.04 & 0.02 & -0.13 & -0.33 & -13.42 & -3.15 \\
\hline IS Shock Std. & $\sigma^{I S}$ & 0.00 & 0.00 & 0.00 & 0.00 & 0.00 & 0.00 \\
\hline PC Shock Std. & $\sigma^{P C}$ & -0.64 & 0.06 & -6.05 & -0.06 & 14.56 & -1.59 \\
\hline \multicolumn{8}{|l|}{ Combined Effects } \\
\hline MP Sub-Total & & 1.07 & -0.79 & 9.04 & 7.68 & -27.00 & 3.41 \\
\hline Shocks Sub-Total & & -0.64 & 0.06 & -6.05 & -0.06 & 14.56 & -1.59 \\
\hline Total Linear Changes & & 0.43 & -0.73 & 2.99 & 7.62 & -12.44 & 1.81 \\
\hline Nonlinearity Effect & & -0.29 & 0.33 & -0.94 & -7.79 & 10.20 & -1.57 \\
\hline
\end{tabular}

We average total derivatives across subsequent periods weighting sub periods according to their sample size. We multiply average weighted total derivatives by the parameter change between subsequent periods. Total derivatives for each sub period are reported in Table 8 and parameter values for each sub period are reported in Table 5. The "MP Sub-Total" row sums the linear effects of $\gamma^{x}, \gamma^{\pi}, \rho^{i}, \bar{\sigma}^{M P}$, and $\bar{\sigma}^{*}$. The "IS\&PC Shocks Sub-Total" row sums the linear effects of $\bar{\sigma}^{I S}$ and $\bar{\sigma}^{P C}$. The row "Total Linear Changes" reports the sum of all linear effects reported in the panel above. The row "Nonlinearity Effect" shows the difference between the model change and the total of linear changes. 
Table 10: Risks of Inflation-Indexed Bonds

\begin{tabular}{lcccccc} 
Panel A: Moments & \multicolumn{2}{c}{ 60.Q1-79.Q2 } & \multicolumn{2}{c}{ 79.Q3-96.Q4 } & \multicolumn{2}{c}{ 97.Q1-11.Q4 } \\
& Empirical & Model & Empirical & Model & Empirical & Model \\
\hline Std. Infl.-Indexed Bond Ret. & N/A & 18.92 & N/A & 5.16 & 4.27 & 2.99 \\
Infl.-Indexed Bond Beta & N/A & -0.88 & N/A & 0.26 & -0.08 & -0.14 \\
\hline
\end{tabular}

Panel B: Marginal Effects of Parameters

Total Derivative 60.Q1- 79.Q3- 97.Q179.Q2 96.Q4 11.Q4

Infl.-Indexed Bond Beta MP Coefficient Output

MP Coefficient Inflation MP Persistence IS Shock Std. PC Shock Std. MP Shock Std. Infl. Target Shock Std.

$\begin{array}{lll}-2.14 & -0.50 & -0.53\end{array}$

$\begin{array}{lll}1.84 & 0.36 & 0.39\end{array}$

$\begin{array}{lll}-0.17 & -0.13 & -2.64\end{array}$

$\begin{array}{lll}0.00 & 0.00 \quad 0.00\end{array}$

$\begin{array}{lll}0.01 & 0.00 \quad 0.00\end{array}$

$\begin{array}{lll}-0.01 & 0.00 & 0.00\end{array}$

$\begin{array}{lll}0.00 & 0.00 \quad 0.00\end{array}$

0.00

0.00

60.Q1- 79.Q3- 97.Q1-

MP Coefficient Output

MP Coefficient Inflation

MP Persistence

IS Shock Std.

PC Shock Std.

MP Shock Std.

Infl. Target Shock Std.

\begin{tabular}{cccccc}
$79 . \mathrm{Q} 2$ & $96 . \mathrm{Q} 4$ & $11 . \mathrm{Q} 4$ & 79.Q2 & 96.Q4 & 11.Q4 \\
\hline 29.84 & -11.35 & 8.19 & & & \\
-26.72 & 8.10 & -6.23 & & & \\
4.00 & -1.92 & 49.35 & & & \\
0.03 & 0.00 & 0.01 & 0.02 & 0.00 & 0.01 \\
16.97 & 1.56 & 0.78 & 17.34 & 1.49 & 0.80 \\
0.50 & 0.32 & 0.57 & 0.11 & 0.51 & 0.50 \\
1.42 & 3.29 & 1.63 & 1.45 & 3.15 & 1.68 \\
\hline
\end{tabular}

Partial Derivative

60.Q1- 79.Q3- 97.Q1-

79.Q2 96.Q4 11.Q4

$\begin{array}{ccc}0.00 & 0.00 & 0.00 \\ -1.64 & 0.17 & -0.09 \\ 0.01 & 0.01 & 0.01 \\ -0.14 & 0.35 & -0.19\end{array}$

\begin{tabular}{lll}
0.02 & 0.00 & 0.01 \\
17.34 & 1.49 & 0.80 \\
0.11 & 0.51 & 0.50 \\
1.45 & 3.15 & 1.68 \\
\hline
\end{tabular}

This table shows the model-implied beta and standard deviation of returns on inflation-indexed bonds with five years to maturity. We approximate inflation-indexed bond log excess returns according to $\widehat{x r}_{5 Y R, t+1}=-19 y_{5 Y R, t+1}^{T I P S}+20 y_{5 Y R, t}^{T I P S}-i_{t}+\pi_{t+1}$, where $y_{5 Y R, t}^{T I P S}$ is the Treasury Inflation Protected (TIPS) end-of-quarter yield with five years to maturity from Bloomberg (USGGT05Y Index). Quarterly TIPS returns are available starting 1997.Q4. We use Newey-West standard errors with 2 lags to assess statistical significance of the empirical bond beta. ${ }^{*}$ and ${ }^{* *}$ denote significance at the $5 \%$ and $1 \%$ levels. 
Figure 1: US Nominal Bond Beta, Bond Volatility, and Policy Dates

Panel A: CAPM Beta of 10 YR Nominal Bond

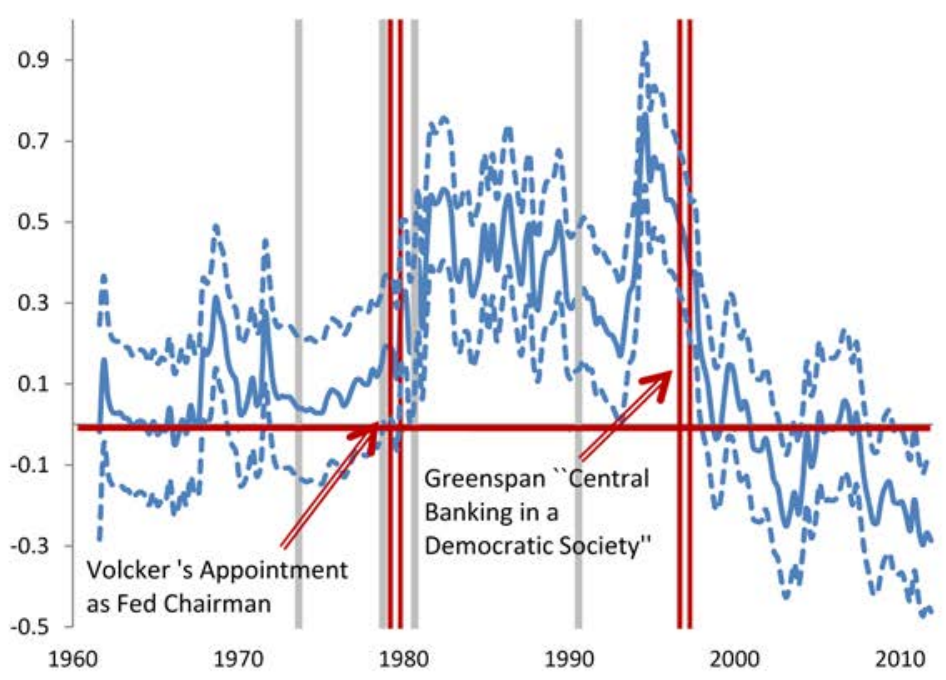

Panel B: Std. of 10 YR Nominal Bond Returns (\%, Ann.)

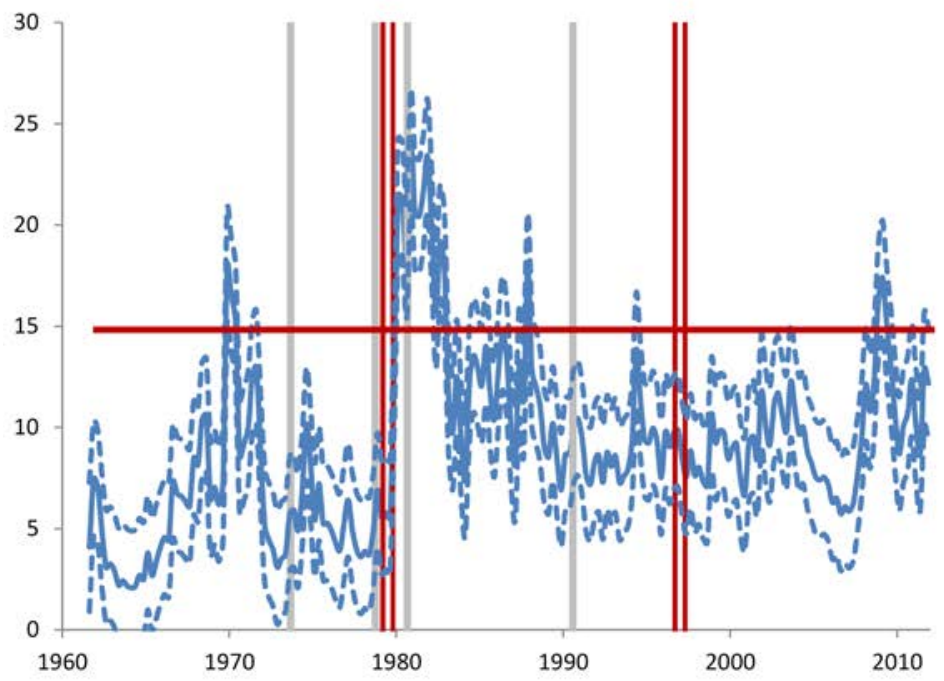

Nominal bond beta and standard deviation of nominal bond returns from daily bond and stock returns over past three months as in Campbell, Sunderam, and Viceira (2013). We model time-varying second moments as an unobserved trend $\operatorname{AR}(1)$ component plus white measurement noise. We show trend second moments estimated using the Kalman filter. 95\% confidence intervals, which do not take into account parameter uncertainty, are shown in dashed. Gray vertical lines depict Hamilton (2009) oil price shocks. 


\section{Figure 2: US Output Gap}

Panel A: Output Gap and Detrended Consumption

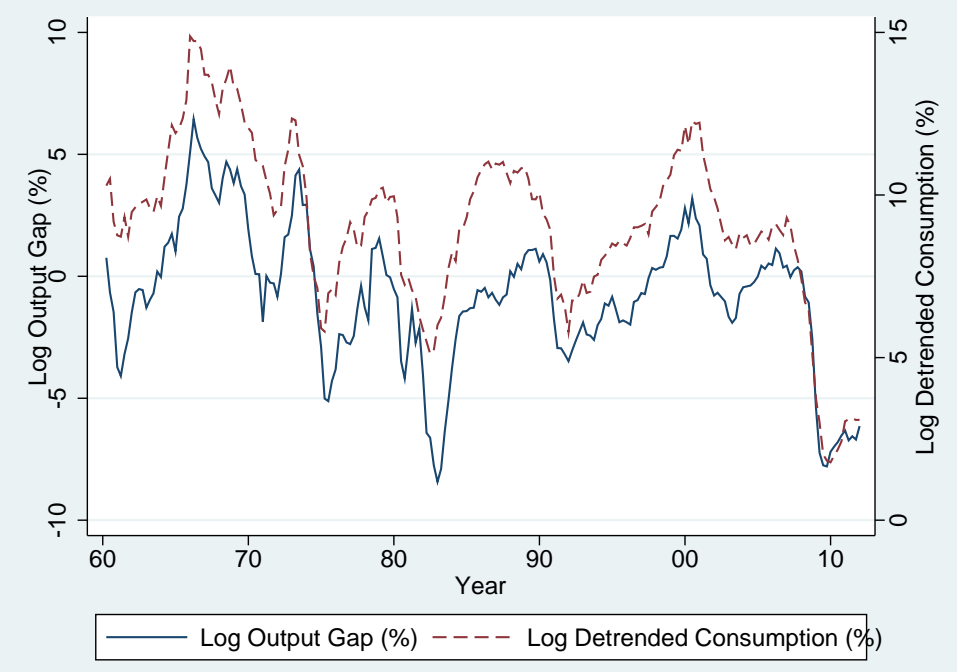

Panel B: Output Gap and Price-Dividend Ratio

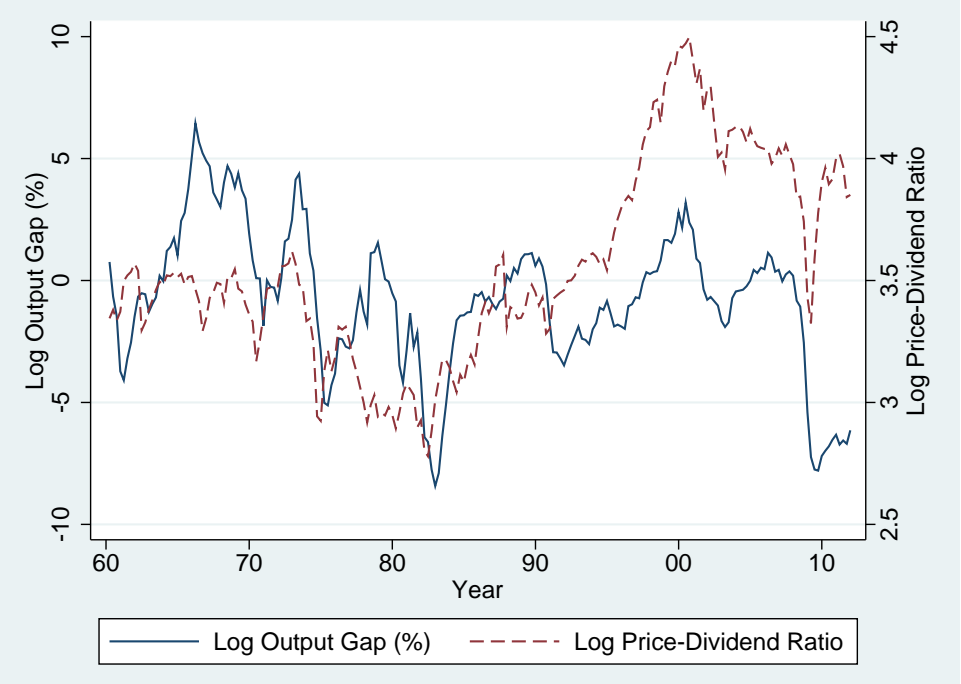

Panel A plots the time series of the US log real output gap together with log real consumption in excess of its 24 quarter moving average. We use real consumption expenditures data for nondurables and services from the Bureau of Economic Analysis National Income and Product Accounts Tables. The US log output gap (\%) is described in Table 1. The end-ofquarter price dividend ratio is computed as the S\&P 500 real price divided by real dividends averaged over the past 10 years. 
Figure 3: Nominal Bond Betas Against Monetary Policy Parameters $\gamma^{\pi}$ and $\gamma^{x}$ Panel A: 1960.Q1-1979.Q2

Panel B: 1979.Q3-1996.Q4
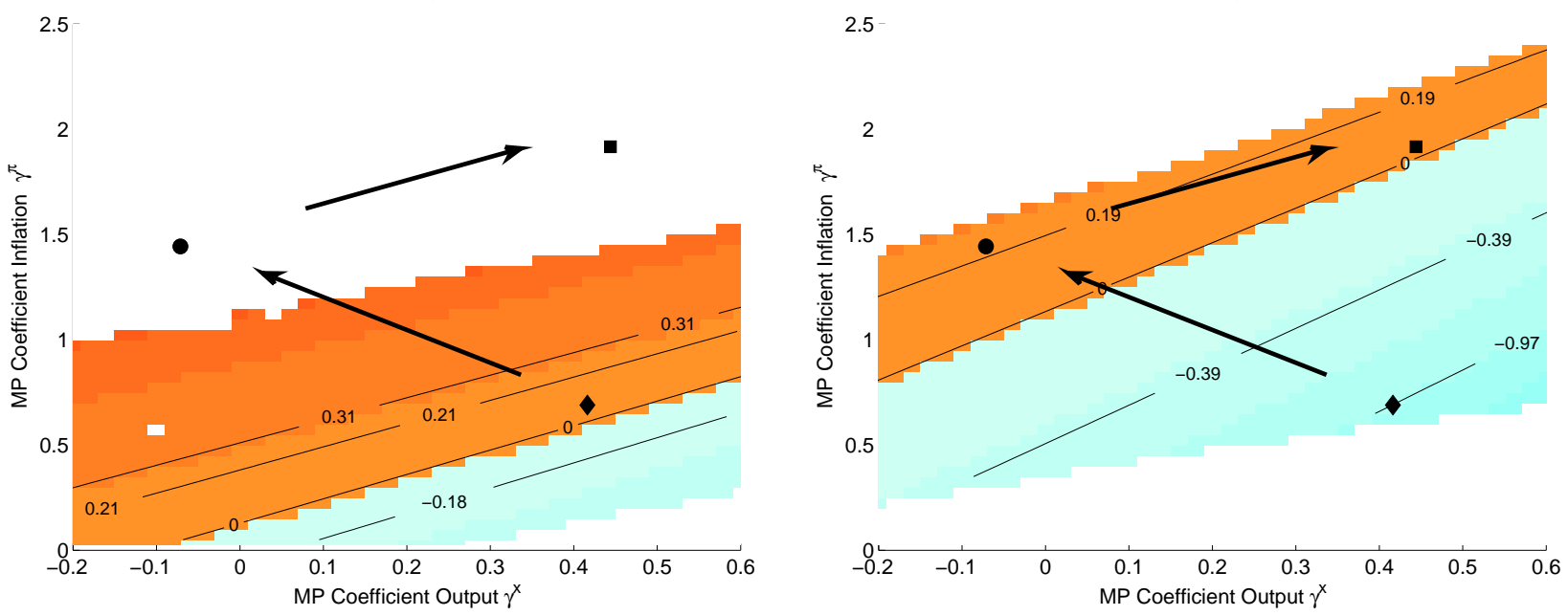

Panel C: 1997.Q1-2011.Q4

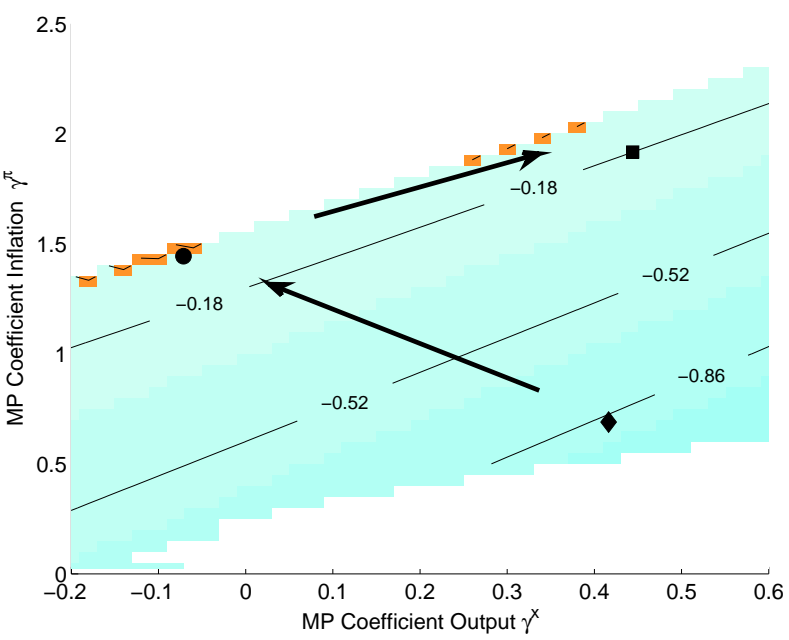

The volatilities of shocks and the monetary policy persistence parameter $\rho^{i}$ are fixed at their calibrated values for 1960.Q1-1979.Q2 (Panel A), 1979.Q3-1996.Q4 (Panel B) or 1997.Q12011.Q4 (Panel C). We indicate calibrated monetary policy parameters as follows: 1960.Q11979.Q2 = diamond, 1979.Q3-1996.Q4 = circle, 1997.Q1-2011.Q4 = square. Arrows connect the sub period monetary policy rules in chronological order. We exclude solutions with an eigenvalue of greater than 0.97 . 
Figure 4: Nominal Bond Betas Against Monetary Policy Parameters $\gamma^{\pi}$ and $\rho^{i}$

Panel A: 1960.Q1-1979.Q2

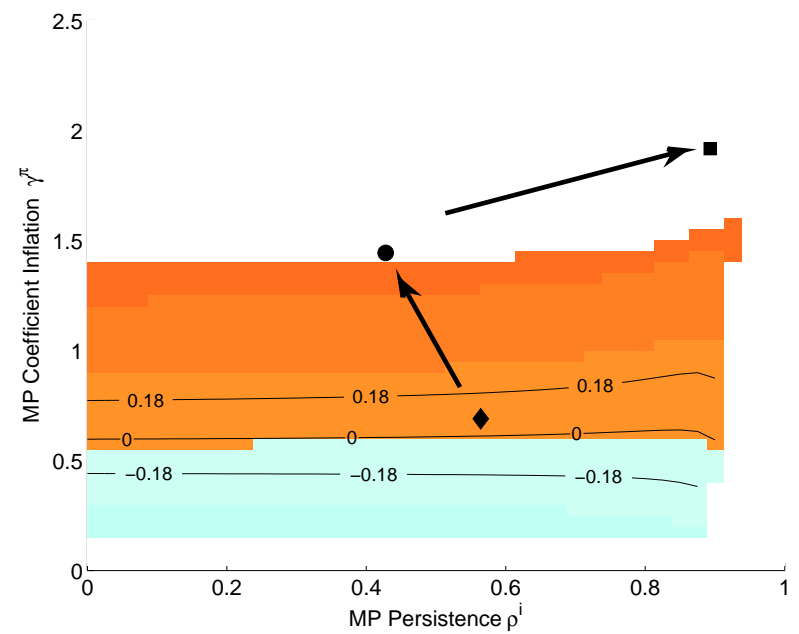

Panel C: 1997.Q1-2011.Q4

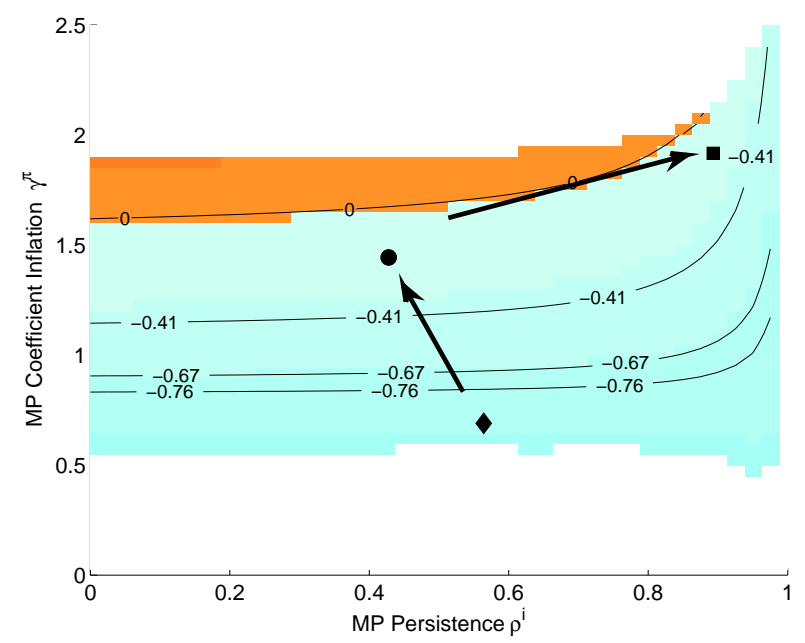

Panel B: 1979.Q3-1996.Q4

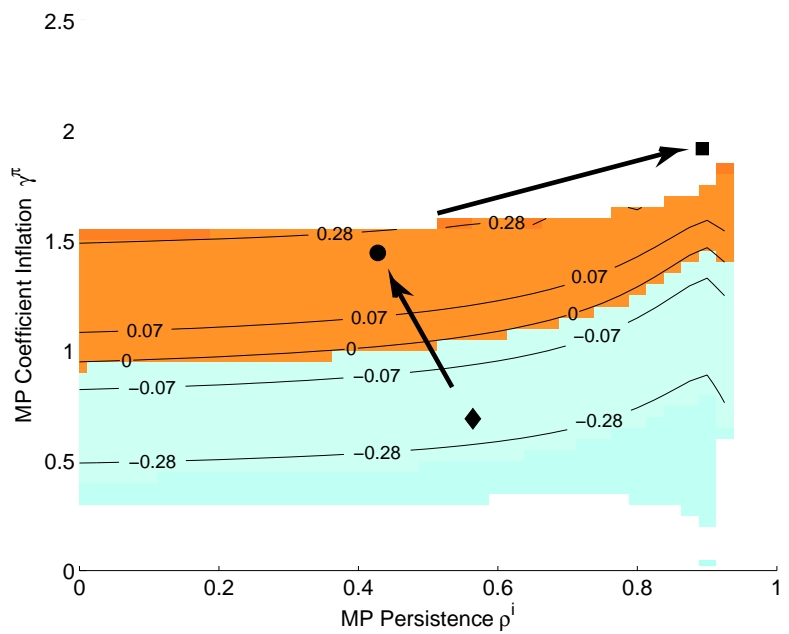

The volatilities of shocks and the monetary policy coefficient $\gamma^{x}$ are fixed at their calibrated values for 1960.Q1-1979.Q2 (Panel A), 1979.Q3-1996.Q4 (Panel B) or 1997.Q1-2011.Q4 (Panel C). We indicate calibrated monetary policy parameters as follows: 1960.Q1-1979.Q2 = diamond, 1979.Q3-1996.Q4 = circle, 1997.Q1-2011.Q4 = square. Arrows connect the sub period monetary policy rules in chronological order. We exclude solutions with an eigenvalue of greater than 0.97 . 
Figure 5: Impulse Response Functions

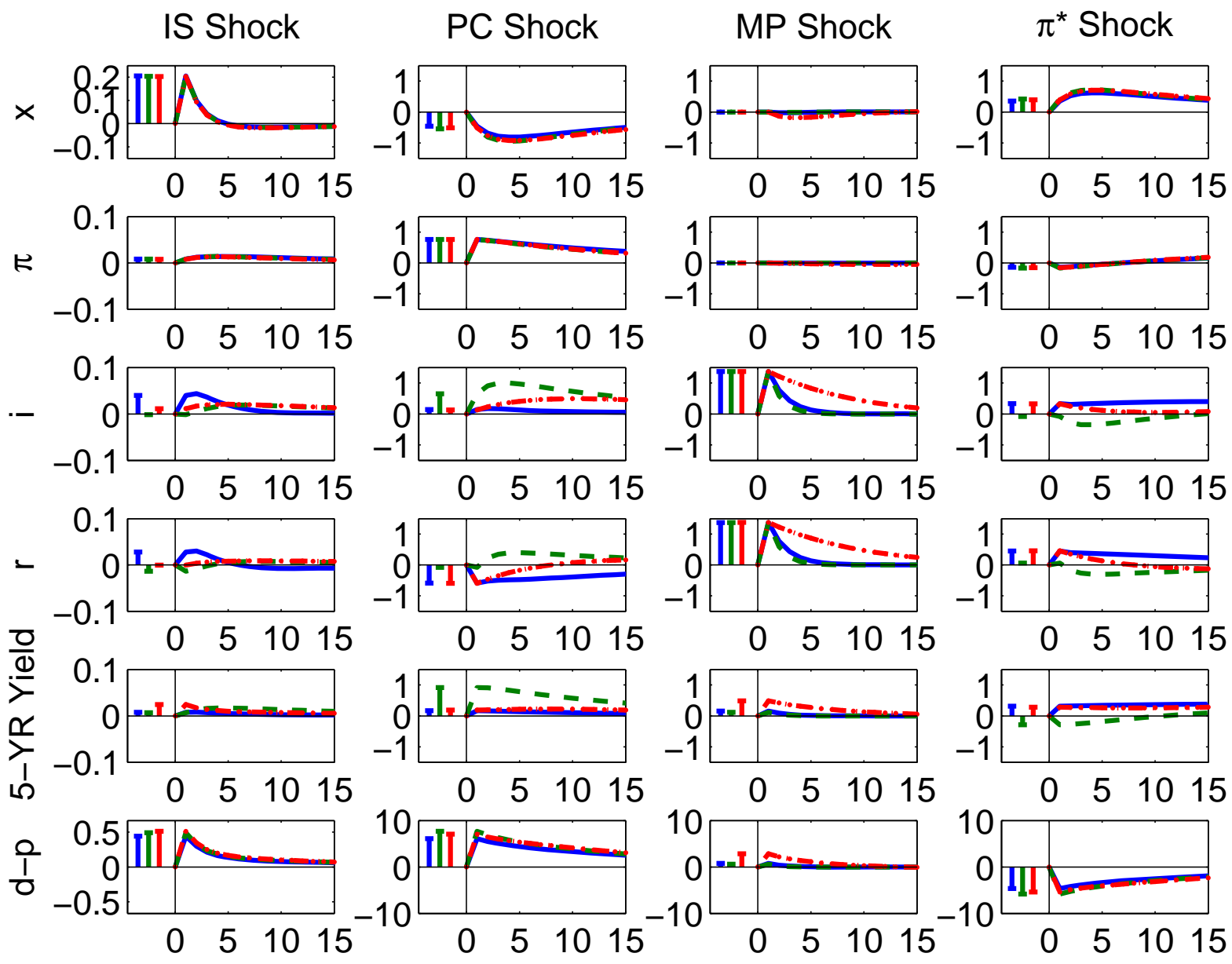

This figure shows impulses for the output gap, inflation, the nominal and real Federal Funds rates, the 5 year nominal yield, and the log dividend price ratio following one standard deviation shocks. We show impulse responses for the subperiods 1960.Q1-1979.Q2 (blue solid line), 1979.Q3-1996.Q4 (green dashed line), and 1997.Q1-2011.Q4 (red dash-dot line). Vertical bars indicate the magnitude of the initial response for each variable for period 1 (blue, left), period 2 (middle, green), and period 3 (red, right). This figure shows impulse responses to the same size shocks for all three subperiods. The shock size equals the average subsample standard deviation, where the average is weighted by sample length. The output gap and the dividend price ratios are in percent deviations from the steady state. All other variables are in annualized percent units. 